\title{
INSUCESSO DE ALUNOS E ALUNAS NO EXAME DE BIOLOGIA E GEOLOGIA: ESTUDO COM PROFESSORES ${ }^{1}$
}

(1) TERESA LOPESI
(1) JOSÉ PRECIOSO"

IUniversidade do Minho (UMinho),Braga, Portugal; teresaflopes@netcabo.pt

" Universidade do Minho (UMinho),Braga, Portugal; precioso@ie.uminho.pt

\section{RESUMO}

O insucesso no exame de Biologia e Geologia em Portugal é muito elevado e tem grande repercussão no prosseguimento de estudos. Esta investigação qualitativa pretendeu averiguar: 1) perceções de professores e professoras sobre as causas de insucesso no exame em função do sexo; 2) opiniões sobre as características da prova; 3) medidas promotoras de sucesso. Recolheram-se dados através de entrevista semidirigida a 15 professores que atribuem o insucesso ao facto de existir exame, às suas características e a dificuldades dos alunos. Sugerem como medidas promotoras de sucesso: redução do programa da disciplina e adequação do grau de dificuldade da prova aos alunos. Os docentes do sexo masculino mostram-se mais preocupados com o insucesso dos rapazes.

PALAVRAs-chaVe AVALIAÇÃO dO RENDIMENTO ESCOLAR • AVALIAÇÃO EXTERNA • EXAME • GÊNERO.

1 Este trabalho é financiado por Fundos Nacionais através da Fundação para a Ciência e a Tecnologia (FCT), no âmbito do projeto do Centro de Investigação em Estudos da Criança (CIEC) da Universidade do Minho, com a referência UID/CED/00317/2019 e através da atribuição de uma bolsa individual de doutoramento (SFRH/BD/123731/2016). 


\section{FRACASO DE ALUMNOS Y ALUMNAS EN LOS EXÁMENES DE BIOLOGÍA Y GEOLOGÍA: ESTUDIO CON PROFESORES}

\section{RESUMEN}

El fracaso en los exámenes de Biología y Geología en Portugal es muy elevado y provoca una gran repercusión en el seguimiento de los estudios. Esta investigación cualitativa pretendió averiguar: 1) percepciones de los docentes sobre las causas de fracaso en los exámenes en función del sexo; 2) opiniones sobre las características de la prueba; 3) medidas que promueven el éxito. Los datos se obtuvieron a través de una entrevista semidirigida a 15 profesores que atribuyen el fracaso al hecho de que exista un examen, a sus características y a dificultades de los alumnos. Para promover el éxito, sugieren: reducción del programa de la asignatura y adecuación del grado de dificultad de la prueba a los alumnos. Los docentes del sexo masculino se muestran más preocupados con el fracaso de los muchachos.

PALABRAS CLAVE EVALUACIÓN DEL RENDIMIENTO ESCOLAR • EVALUACIÓN EXTERNA • EXAMEN • GÉNERO.

\section{FAILURE OF MALE AND FEMALE STUDENTS IN THE BIOLOGY AND GEOLOGY EXAM: STUDY WITH TEACHERS}

\section{ABSTRACT}

Failure in the Biology and Geology exam in Portugal is very high and has significant impacts on further studies. This qualitative research aimed to investigate: 1) the perceptions of teachers about the causes of failure in the exam as a function of gender; 2) opinions about the test characteristics; 3) measures to promote success. Data were collected through semi-directed interviews with 15 teachers who attribute the failure to the exam itself, its characteristics and students' difficulties. To promote success, they suggest measures such as: reducing the subject syllabus and adapting the level of difficulty of the test to the students' capacity. Male teachers seem to be more concerned about boys' failure.

KEYWORDS ASSESSMENT OF SCHOOL ACHIEVEMENT • EXTERNAL ASSESSMENT • EXAM - GENDER. 


\section{INTRODUÇÃO}

Em Portugal, a conclusão e certificação do ensino secundário, assim como o acesso ao ensino superior, estão dependentes de um sistema de avaliação em que a avaliação externa, sob a forma de exames, tem grande impacto. Portanto, os resultados nas provas nacionais de Biologia e Geologia têm demasiada influência no futuro académico e, por consequência, profissional dos alunos e alunas. Todavia, estes resultados têm sido, ao longo dos anos, desanimadores, sem apresentar melhorias, com as médias a situar-se entre os 8 e os 10 valores (numa escala de 0 a 20 valores) e as taxas de reprovação no exame entre 45 e 65\% - dados de 2013 a 2017. As raparigas, de uma forma geral, têm conseguido alcançar melhores resultados do que os rapazes, conseguindo atingir classificações médias ligeiramente superiores e taxas de reprovação inferiores (LOPES; PRECIOSO, 2018).

Têm sido feitos estudos para investigar as causas do insucesso dos alunos nos exames nacionais, mas não por sexo, o que torna o nosso estudo inovador, visto que entrevistamos professores e professoras para procurar explicações para as causas do diferente desempenho, assim como as razões das diferenças de reprovação entre rapazes e raparigas, uma vez que só compreendendo bem este fenómeno poderemos introduzir medidas promotoras de sucesso e de equidade.

Assim, este artigo apresenta-se estruturado da seguinte forma: contextualização teórica, discutindo a avaliação externa, as suas limitações e potencialidades, a influência dos exames nas práticas dos professores e as diferenças no desempenho escolar por sexo; definição de objetivos; metodologia; apresentação dos resultados; e, por fim, discussão dos resultados e conclusões.

\section{AVALIAÇÃO EXTERNA}

\section{O contexto português}

Como ponto de partida, será importante clarificar o sistema de avaliação externa, no ensino secundário, na realidade portuguesa. Em Portugal, a avaliação externa operacionaliza-se através de exames nacionais, testes normalizados da responsabilidade das autoridades educativas nacionais, que têm por objetivos avaliar o desempenho dos alunos e certificar a conclusão do ensino secundário, mas também hierarquizar os alunos para o acesso ao ensino superior.

No nosso país, a escolaridade obrigatória estende-se até ao final do ensino secundário (ou 18 anos de idade), que compreende três anos de escolaridade: $10^{\circ}, 11^{\circ}$ e $12^{\circ}$ anos. De entre várias vias possíveis, os cursos científico-humanísticos constituem a oferta educativa com mais alunos (PORTUGAL, 2018). É a via vocacionada para o prosseguimento de estudos no ensino superior e a sua certificação depende da realização de exames. A disciplina de Biologia e Geologia é lecionada nos $10^{\circ}$ e $11^{\circ}$ 
anos e integra a componente específica do curso científico-humanístico de Ciências e Tecnologias. Nesta área científica, os alunos realizam obrigatoriamente, no final do $11^{\circ}$ ano, os exames das duas disciplinas bienais da componente de formação específica, Biologia e Geologia, Física e Química ou Geometria Descritiva; e, no final do $12^{\circ}$ ano, exame de Português e de Matemática.

Para cálculo da classificação final de cada disciplina sujeita a exame, a nota interna atribuída pelo professor tem peso de $70 \%$, e a nota obtida no exame tem um peso de $30 \%$. Mas, para seriação dos alunos no acesso ao ensino superior, a classificação no exame também tem um peso que pode chegar a 50\% no cálculo da média de acesso, se a disciplina for obrigatória para ingresso num determinado curso, sendo necessária a nota mínima de 9,5 valores no exame para os alunos se poderem candidatar a esse curso.

Desta forma, os exames têm grande impacto no percurso escolar dos alunos, na vida profissional dos professores e na imagem social das escolas, adquirindo uma dimensão de absoluta preponderância, transformando-se na meta a alcançar de todo o ensino secundário.

\section{Discutindo as limitações e as potencialidades}

A avaliação externa sempre foi um tema controverso, sendo um "espaço de conflito" (GARCIA, 2004), mas, embora o verdadeiro impacte dos exames nacionais no desempenho dos alunos, nas escolas e nos sistemas educativos exija mais investigação na área (MONS, 2009), continua a fazer parte das políticas públicas de educação de vários países (FERNANDES, 2014). Particularmente desde a década de 1990, esta modalidade de avaliação foi sendo introduzida em quase todos os países europeus com o propósito de regulação dos sistemas educativos, justificada politicamente pelas progressivas descentralização e autonomia das escolas (EURYDICE, 2009). Desta forma, os resultados dos alunos são usados para monitorizar e supervisionar o trabalho das escolas, no sentido de aumentar a qualidade de ensino e a eficácia dos sistemas educativos (EURYDICE, 2009), embora nunca se tenha estabelecido uma relação de causa e efeito entre a aplicação de exames e uma maior qualidade das aprendizagens ou dos sistemas educativos (FERNANDES, 2014). Estas são as fundamentações para as avaliações estandardizadas, nacionais e internacionais, terem proliferado, durante as últimas décadas (VERGARA, 2017), aceitando-se que os sistemas educativos passassem a ser geridos através da prestação de contas.

A avaliação externa, embora socialmente esteja associada a uma imagem de exigência, de rigor e de qualidade dos sistemas de ensino, tem, como afirma Fernandes (2014), funções que não visam à melhoria das aprendizagens e que, portanto, não visam à melhoria dos sistemas de ensino: a função de controlo (o controlo do cumprimento do programa das disciplinas), função de monitorização (através 
da responsabilização de alunos, professores e escolas e prestação de contas pelos resultados dos alunos), a certificação das aprendizagens e a seleção dos alunos no acesso ao ensino superior. Todavia, segundo este autor, os exames apresentam algumas vantagens:

a) o efeito moderador que têm sobre as avaliações internas; b) a indução de práticas inovadoras de ensino e de avaliação; c) a contribuição para se compreender melhor o desempenho dos sistemas educativos, melhorando a tomada de decisões; d) a informação que podem proporcionar às escolas, aos professores e aos alunos relativamente ao que é importante ensinar e aprender; e e) a mobilização das escolas e dos professores para a eventual necessidade de reverem os seus processos de trabalho, nomeadamente no que se refere aos projetos educativos e à organização e desenvolvimento do ensino. (FERNANDES, 2014, p. 297-298)

Contudo, no sentido de discutirmos estas vantagens apontadas dos exames, salientamos o facto de, pelo menos em nosso país, estas provas não induzirem práticas inovadoras, mas sim práticas de treino para o exame e de transmissão de conhecimentos, sem diversificação de metodologias, para os professores terem tempo de lecionar todos os conteúdos programáticos, como se verá nos resultados deste estudo. Além disso, os exames têm reforçado as conceções psicométricas da avaliação. É verdade que, no sistema de ensino português, em termos normativos, a avaliação tem progredido de uma avaliação de classificação e certificação para uma avaliação para a melhoria e desenvolvimento das aprendizagens e do ensino (FERNANDES, 2007), já que a legislação define a avaliação formativa como a principal modalidade avaliativa, inclusivamente no ensino secundário. No entanto, as mudanças na legislação não implicam obrigatoriamente mudanças das práticas dentro da sala de aula, onde a avaliação sumativa continua a ter prevalência em relação à avaliação formativa (FERNANDES, 2007), potenciada, no ensino secundário, pela existência de exames.

Por outro lado, a utilização que se faz dos resultados dos alunos nos exames também não tem sido aproveitada para induzir melhorias no nosso sistema educativo, basta ver como os resultados nas provas nacionais se têm mantido tão insatisfatórios sem mostrar progressos, já que as médias se mantêm invariavelmente baixas, e as taxas de reprovação, persistentemente altas, como mostram estudos de monitorização (LOPES; PRECIOSO, 2018). Por outro lado, vários estudos (MADUREIRA, 2011; SOUSA, 2011; SALGADO, 2012; LOPES, 2013) mostram que os professores têm vindo a modificar as suas práticas pedagógicas e avaliativas no sentido de adaptação dos alunos ao que é pedido no exame para que estes tenham sucesso: trabalham nas aulas questões 
de exame, realizam as suas próprias fichas de avaliação com questões semelhantes às dos exames e utilizam os mesmos critérios de avaliação. Além disso, os alunos têm acesso aos exames dos anos anteriores para "treinar" para a prova, o que deveria estar a levar a melhorias nos resultados dos alunos, o que não se verifica.

Fernandes (2014) também apresenta desvantagens da avaliação externa, das quais salienta o efeito redutor que os exames têm no currículo, dando-se uma supremacia total ao que supostamente é avaliado nos exames. Só são valorizados os conteúdos, as competências, as disciplinas que são examinados. Desta forma, toda a formação do aluno fica reduzida e empobrecida. Uma outra desvantagem apontada por Fernandes (2014) relaciona-se à implantação de práticas de discriminação e exclusão de alunos, particularmente de alunos provenientes de meios económicos e sociais mais frágeis, já que as escolas e os professores podem ser impelidos a empreenderem mais esforços nos alunos que poderão ter mais sucesso nos exames, em prejuízo dos alunos que revelem dificuldades ou dos alunos cujas expetativas de sucesso sejam baixas, pressionando-os para não fazerem o exame ou para saírem da escola, podendo levar à retenção e ao abandono escolar precoce.

Importa, então, devolver aos exames a sua real dimensão: “[...] os exames nacionais não representam mais do que uma imagem instantânea do nível educativo do aluno num determinado momento e em apenas alguns domínios” (EURYDICE, 2009, p. 61).

\section{Influência dos exames nas práticas dos professores}

Os exames nacionais do ensino secundário português, tendo a função de certificação e de seleção de estudantes para o ensino superior, assumem uma grande importância para alunos e encarregados de educação. Por outro lado, o facto de os resultados dos alunos serem publicados pela comunicação social sob a forma de rankings leva a que esses resultados se transformem na imagem social de sucesso ou insucesso de professores e escolas. Estes fatores criam uma grande pressão sobre alunos, professores e escolas, o que faz com que o quotidiano escolar se centre na preparação para as provas nacionais, o que se tem vindo a chamar no meio académico de "teaching to the test", passando todo o processo de aprendizagem a concentrar-se nos resultados dos alunos nas provas nacionais, e não na qualidade dos processos de desenvolvimento das aprendizagens. O exame transforma-se na meta a atingir, deixando de ser um dos instrumentos de avaliação que faz parte do processo educativo dos alunos, deturpando o processo educativo porque se renuncia à qualidade dos processos e contextos das aprendizagens pela supremacia dos resultados dos alunos (NAVAS; ALCARAZ; SOLA, 2017).

Vários estudos realizados no nosso país (RAPOSO; FREIRE, 2008; MADUREIRA, 2011; SOUSA, 2011; LOPES, 2013; MARQUES et al., 2015) mostram a influência clara 
da realização de exames nacionais nas práticas pedagógicas e avaliativas dos professores. Os docentes orientam as suas práticas no sentido de "treinar" os alunos para o que é pedido no exame, procurando os melhores resultados possíveis. Para tal, utilizam práticas que não pensam ser as de maior qualidade para a aprendizagem, passaram a fazer os seus testes com a estrutura semelhante à dos exames e a utilizar os mesmos critérios de correção e classificação das questões, mesmo não concordando com eles e considerando-os penalizadores para os alunos, no sentido de adaptar os alunos às condições que terão de enfrentar nos exames nacionais. Têm grande preocupação em abordar todo o programa das disciplinas, mesmo sabendo que o ritmo que impõem para o lecionar não proporciona uma aprendizagem de qualidade (LOPES, 2013).

Segundo o relatório da Organização para a Cooperação e o Desenvolvimento Económico (OCDE) Reviews of Evaluation and Assessment in Education: Portugal 2012 (SANTIAGO et al., 2012), a sala de aula e todo o processo de aprendizagem, em Portugal, continuam a organizar-se de forma tradicional, sendo o professor o centro do processo, o mesmo acontecendo com a avaliação que se concentra nos resultados sumativos. Os alunos, normalmente, não são envolvidos na planificação e organização das aulas nem na avaliação. O feedback dado aos estudantes e encarregados de educação sobre o desenvolvimento dos alunos tende a concentrar-se no desempenho e nos resultados dos testes, e não na aprendizagem. O relatório chama a atenção para o facto de a avaliação formativa ser claramente suplantada pela avaliação sumativa, como consequência de os professores se focarem nos resultados dos alunos e de uma prática em sala de aula dominada pelo exame e preparação dos testes. Para a equipa da OCDE que analisou o sistema de ensino português, é claro que as políticas educativas relacionadas à avaliação têm vindo a enfatizar o accountability. O desafio lançado a Portugal é o de encontrar o equilíbrio certo entre essas duas funções da avaliação: a função de prestação de contas e a função de promoção de melhorias e de sucesso.

\section{Diferenças no desempenho escolar por sexo}

As diferenças no desempenho escolar entre rapazes e raparigas têm sido alvo de atenção e estudo por parte da investigação a nível internacional, prova disso são os vários indicadores medidos por sexo nas avaliações estandardizadas em larga escala, como é o caso do Programme for International Student Assessment (PISA). No entanto, em Portugal, os estudos na área são escassos, e esta problemática tem vindo a ser desvalorizada (CAVACO et al., 2015).

Segundo o Relatório da OCDE The ABC of Gender Equality in Education: Aptitude, Behaviour, Confidence, de 2015, nos países da OCDE, de uma forma generalizada, a hierarquia de género a nível educacional foi invertida. Se, em 2000, a taxa de homens 
com ensino superior suplantava a taxa de mulheres, em 2012, os números já se tinham invertido, sendo que 34\% das mulheres nos países da OCDE tinham já alcançado o ensino superior, enquanto que, entre os homens, essa percentagem era de $30 \%$, tendência que parece ser ainda mais acentuada entre alunos e alunas com menos de 25 anos. Segundo o mesmo relatório, os rapazes sentem-se menos inseridos e interessados na escola, apresentando baixas qualificações e baixo desempenho académico, são mais propensos a abandonar a escola de forma precoce, frequentemente sem qualificações, e consideram mais que a escola é uma perda de tempo.

No nosso país, as taxas de insucesso e de abandono precoce da escola são mais elevadas entre os rapazes do que entre as raparigas (CAVACO et al., 2015). A taxa de conclusão do ensino secundário nos cursos científico-humanísticos em Portugal, dados relativos ao ano letivo 2017/2018, é também favorável às raparigas: total de alunos é de 74\%; rapazes, 69,4\%; raparigas, 77,6\% (PORTUGAL, 2019). Dados referentes ao ano letivo de 2016/2017 (PORTUGAL, 2018) mostram que a percentagem de rapazes e de raparigas entre os alunos que concluíram o curso científico-humanístico de Ciências e Tecnologias é relativamente equilibrada, embora vantajosa para as raparigas: $52 \%$ foram raparigas e $48 \%$ foram rapazes. Todavia, o desequilíbrio surge quando analisamos a percentagem dos alunos diplomados em Ciências e Tecnologias que escolheram e concluíram a disciplina de Biologia e Geologia por sexo: rapazes foram $87 \%$ e raparigas, $97 \%$.

Estudos anteriores efetuados por nós (LOPES; PRECIOSO, 2018) mostram que, de uma forma geral, as raparigas têm tido um melhor desempenho relativamente aos rapazes nos exames de Biologia e Geologia, alcançando classificações médias ligeiramente superiores e taxas de reprovação na prova inferiores.

O relatório Abandono e insucesso escolar: construir uma perspetiva de género, realizado em 2015 (CAVACO et al., 2015), conclui que os professores portugueses não têm conhecimento de que as taxas de insucesso e de abandono precoce da escola são mais elevadas entre os rapazes do que entre as raparigas. Os docentes reconhecem que o tema não é abordado no ambiente escolar, ou seja, não refletem o insucesso e o abandono escolar numa perspetiva de género, o que é particularmente preocupante, porque Portugal é um dos países da União Europeia onde a diferença de género no desempenho escolar é mais elevada. A verdade é que vários países têm vindo já a trabalhar na paridade de género nos resultados escolares (OCDE, 2015), e, em Portugal, esse problema nem sequer é reconhecido pelos professores.

\section{OBJETIVOS}

Os objetivos deste estudo são os seguintes: 1) averiguar as perceções dos professores e professoras sobre as causas de insucesso na disciplina de Biologia e Geologia 
em função do sexo; 2) averiguar as perceções dos professores e professoras sobre as causas de insucesso no exame de Biologia e Geologia em função do sexo; 3) averiguar as perceções dos professores e das professoras sobre as características do exame de Biologia e Geologia; 4) apurar medidas para promover o sucesso na aprendizagem e no exame da disciplina de Biologia e Geologia; 5) analisar as diferenças entre as perceções de professores e professoras.

\section{METODOLOGIA}

\section{Tipo de estudo}

Trata-se de uma investigação qualitativa exploratória, na qual os dados foram recolhidos através da técnica de inquérito por entrevista, com o objetivo de aprofundar ideias, opiniões e conceções dos professores e professoras entrevistados.

\section{Amostra}

A amostra do estudo é constituída por 15 professores do quadro de Escola/ Agrupamento, oito mulheres e sete homens, do grupo de Biologia e Geologia, grupo de docência 520, que tenham lecionado os $10^{\circ}$ e/ou $11^{\circ}$ anos em escolas do distrito de Braga, no norte de Portugal. Na seleção dos participantes, considerou-se a diversidade em termos de área geográfica, tendo-se entrevistado docentes dos concelhos de Braga, Famalicão, Guimarães e Vizela, pertencentes a sete escolas públicas diferentes, com dimensões variadas. Quanto ao tempo de serviço docente, todos têm mais de 20 anos de serviço, o que revela uma amostra composta por professores experientes profissionalmente.

\section{Instrumento de recolha de dados}

Foi elaborado um protocolo de entrevista semidirigida de forma a permitir obter dados sobre as seguintes dimensões relacionadas aos objetivos da investigação: averiguar as perceções dos professores sobre as causas de insucesso escolar da disciplina de Biologia e Geologia; averiguar as perceções dos professores sobre as causas das diferenças de insucesso escolar da disciplina de Biologia e Geologia em rapazes e raparigas; averiguar as perceções dos professores sobre a influência do Exame Nacional no insucesso escolar da disciplina de Biologia e Geologia; averiguar as perceções dos professores sobre as causas de insucesso no exame de Biologia e Geologia; averiguar as perceções dos professores sobre as causas das diferenças no insucesso no exame de Biologia e Geologia de rapazes e raparigas; averiguar as representações da influência da realização do exame nacional nas práticas pedagógicas e de avaliação dos professores; identificar as opiniões dos professores sobre as características do exame nacional de Biologia e Geologia; averiguar as medidas 
sugeridas pelos professores para promover o sucesso na aprendizagem da disciplina de Biologia e Geologia; averiguar as medidas sugeridas pelos professores para promover o sucesso no exame de Biologia e Geologia.

\section{Validação do protocolo de entrevista}

O protocolo de entrevista foi enviado a especialistas para que procedessem à sua análise. Levaram-se em consideração as sugestões de melhoria dos especialistas para reformulação do guião de entrevista, no sentido de nos certificarmos de que se recolheriam dados válidos que permitissem a consecução dos objetivos da investigação.

\section{Recolha de dados}

As entrevistas foram realizadas pela investigadora, no ano letivo 2018/2019, de forma individual, garantindo aos entrevistados o anonimato, a confidencialidade das respostas e a exclusiva utilização da informação para a finalidade da investigação. Foram efetuadas mediante marcação prévia de dia e hora, de acordo com a disponibilidade dos entrevistados, em local escolhido pelos inquiridos. As entrevistas foram gravadas em suporte de áudio, com a concordância dos participantes e, posteriormente, foram transcritas para análise de conteúdo.

\section{Tratamento de dados}

A análise de conteúdo foi realizada com recurso ao programa MAXQDA, um software para análise de dados qualitativos. Para cada questão, definiram-se a posteriori categorias de resposta que advieram do discurso dos entrevistados. Por fim, organizaram-se e registaram-se os dados em quadros, organizados por dimensões com as respetivas categorias de resposta, registando-se a presença/ausência de cada uma das categorias.

\section{RESULTADOS}

Perceções dos professores sobre as causas de insucesso na disciplina de Biologia e Geologia

Os professores apresentam 13 diferentes razões para justificar o insucesso dos alunos na avaliação interna da disciplina de Biologia e Geologia (BG), registadas no Quadro 1. A principal causa apresentada (nove professores, cinco homens e quatro mulheres) é a existência de exame nacional que condiciona o funcionamento da disciplina, tanto no que diz respeito às práticas pedagógicas e avaliativas dos professores como relativamente às atitudes dos alunos perante a disciplina. P15 afirma: "[...] como a disciplina é sujeita a exame, utilizam-se critérios de avaliação muito 
apertados. Depois, os testes são equivalentes aos exames. É como se, em cada teste, os miúdos estivessem a fazer exame”.

\section{QUADRO 1 - Perceções dos professores sobre as causas de insucesso na disciplina de BG}

\begin{tabular}{|c|c|c|c|c|c|c|c|c|c|c|c|c|c|c|c|c|c|c|}
\hline \multirow[b]{2}{*}{$\begin{array}{l}\text { CAUSAS DO } \\
\text { INSUCESSO EM BG }\end{array}$} & \multicolumn{8}{|c|}{ HOMENS } & \multicolumn{9}{|c|}{ MULHERES } & \multirow[b]{2}{*}{ 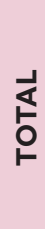 } \\
\hline & P1 & $\mathbf{P 2}$ & P3 & P4 & P5 & P6 & P7 & $\begin{array}{l}\frac{1}{5} \\
\frac{5}{\circ} \\
\frac{m}{2} \\
\end{array}$ & P8 & P9 & P10 & P11 & P12 & P13 & P14 & P15 & 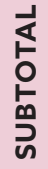 & \\
\hline Existência de exame & $\checkmark$ & $\checkmark$ & $\checkmark$ & $\checkmark$ & & $\checkmark$ & & 5 & & & $\checkmark$ & $\checkmark$ & & & $\checkmark$ & $\checkmark$ & 4 & 9 \\
\hline $\begin{array}{l}\text { Programa demasiado } \\
\text { extenso }\end{array}$ & & $\checkmark$ & & & & $\checkmark$ & & 2 & $\checkmark$ & $\checkmark$ & $\checkmark$ & & $\checkmark$ & $\checkmark$ & $\checkmark$ & & 6 & 8 \\
\hline $\begin{array}{l}\text { Elevado grau de } \\
\text { dificuldade da disciplina }\end{array}$ & $\checkmark$ & $\checkmark$ & $\checkmark$ & & & & $\checkmark$ & 4 & & $\checkmark$ & & & & & $\checkmark$ & $\checkmark$ & 3 & 7 \\
\hline $\begin{array}{l}\text { Desajuste entre grau de } \\
\text { dificuldade do ensino } \\
\text { básico e do ensino } \\
\text { secundário }\end{array}$ & & $\checkmark$ & $\checkmark$ & & & $\checkmark$ & & 3 & & & $\checkmark$ & & $\checkmark$ & & $\checkmark$ & $\checkmark$ & 4 & 7 \\
\hline $\begin{array}{l}\text { Falta de interesse, } \\
\text { motivação, empenho dos } \\
\text { alunos }\end{array}$ & & & $\checkmark$ & $\checkmark$ & $\checkmark$ & & $\checkmark$ & 4 & & $\checkmark$ & & & $\checkmark$ & & & $\checkmark$ & 3 & 7 \\
\hline $\begin{array}{l}\text { Dificuldades de } \\
\text { leitura, interpretação } \\
\text { e comunicação oral e } \\
\text { escrita }\end{array}$ & & $\checkmark$ & & & & & $\checkmark$ & 2 & & & $\checkmark$ & & & $\checkmark$ & & & 2 & 4 \\
\hline $\begin{array}{l}\text { Abordagem muito } \\
\text { teórica da disciplina }\end{array}$ & & & & & & $\checkmark$ & & 1 & $\checkmark$ & & $\checkmark$ & & & $\checkmark$ & & & 3 & 4 \\
\hline $\begin{array}{l}\text { Estudo direcionado para } \\
\text { a memorização }\end{array}$ & & & & & & $\checkmark$ & & 1 & & & & & & $\checkmark$ & & & 1 & 2 \\
\hline $\begin{array}{l}\text { Horário escolar } \\
\text { demasiado pesado }\end{array}$ & & & & $\checkmark$ & & & & 1 & & $\checkmark$ & & & & & & & 1 & 2 \\
\hline $\begin{array}{l}\text { Falta de qualidade do } \\
\text { professor }\end{array}$ & & & & $\checkmark$ & & & & 1 & & & & & & & & & 0 & 1 \\
\hline $\begin{array}{l}\text { Falta de maturidade dos } \\
\text { alunos }\end{array}$ & & & & $\checkmark$ & & & & 1 & & & & & & & & & 0 & 1 \\
\hline $\begin{array}{l}\text { Contexto familiar/social } \\
\text { desfavorecido }\end{array}$ & $\checkmark$ & & & & & & & 1 & & & & & & & & & 0 & 1 \\
\hline $\begin{array}{l}\text { Desatualização do } \\
\text { programa da disciplina }\end{array}$ & $\checkmark$ & & & & & & & 1 & & & & & & & & & 0 & 1 \\
\hline
\end{tabular}

Fonte: Elaboração dos autores.

Apontam também como uma das principais causas (oito professores: dois homens e seis mulheres) a extensão exagerada do programa que condiciona a abordagem pedagógica da disciplina devido ao tempo necessário para lecionar todos os conteúdos, como explica P13: "É sempre uma luta constante e um stress constante entre cumprir o programa, mas, de uma certa forma, aplicar estratégias que possam permitir aos alunos desenvolver competências que vão ser exigidas em exame”. Mencionam ainda (sete professores: três homens e quatro mulheres) que há um desajuste entre o grau de dificuldade do ensino básico e do ensino secundário 
que provoca um efeito de "choque" nos alunos, sendo necessário um período de adaptação à nova realidade para o qual não há tempo. Referem também (sete professores: quatro homens e três mulheres) a falta de interesse, motivação e empenho dos alunos.

Relativamente às diferenças entre homens e mulheres, é visível a maior preocupação das professoras com a dimensão exagerada do programa e como isso influencia o funcionamento da disciplina, sendo também elas as mais preocupadas com a abordagem teórica da disciplina. Por outro lado, enquanto os professores apresentam 13 causas para explicar o insucesso dos alunos na aprendizagem da disciplina, as professoras apresentam apenas nove motivos. Ou seja, são os professores do sexo masculino que diversificam mais as suas explicações para o insucesso dos alunos.

\section{Perceções dos professores sobre o insucesso na disciplina de Biologia e Geologia por sexo}

Quando questionados sobre as suas perceções e experiências sobre o insucesso na disciplina em função do sexo (Quadro 2), dez professores, quatro homens e seis mulheres, percecionam diferenças, considerando que o insucesso é superior entre os rapazes. Os restantes não percecionam diferenças, e nenhum considera o insucesso superior entre as raparigas. No entanto, é de salientar que se percebe pelo seu discurso que os docentes nunca tinham pensado muito na questão do insucesso por sexo.

\section{QUADRO 2 - Perceções dos professores sobre o insucesso na disciplina de BG, por sexo}

\begin{tabular}{|c|c|c|c|c|c|c|c|c|c|c|c|c|c|c|c|c|c|c|}
\hline \multirow[b]{2}{*}{$\begin{array}{l}\text { INSUCESSO NA } \\
\text { DISCIPLINA POR SEXO }\end{array}$} & \multicolumn{8}{|c|}{ HOMENS } & \multicolumn{9}{|c|}{ MULHERES } & \multirow[b]{2}{*}{$\begin{array}{l}\frac{1}{\leftarrow} \\
\stackrel{0}{\circ}\end{array}$} \\
\hline & P1 & P2 & P3 & P4 & P5 & P6 & P7 & 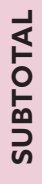 & P8 & P9 & P10 & P11 & P12 & P13 & P14 & P15 & $\begin{array}{l}\frac{1}{5} \\
\frac{1}{\circ} \\
\frac{1}{\infty} \\
2 \\
\end{array}$ & \\
\hline $\begin{array}{l}\text { O insucesso é superior } \\
\text { entre as raparigas }\end{array}$ & & & & & & & & 0 & & & & & & & & & 0 & 0 \\
\hline $\begin{array}{l}\text { O insucesso é superior } \\
\text { entre os rapazes }\end{array}$ & $\checkmark$ & & & $\checkmark$ & $\checkmark$ & & $\checkmark$ & 4 & $\checkmark$ & $\checkmark$ & & $\checkmark$ & $\checkmark$ & $\checkmark$ & $\checkmark$ & & 6 & 10 \\
\hline $\begin{array}{l}\text { Não perceciona } \\
\text { diferenças }\end{array}$ & & $\checkmark$ & $\checkmark$ & & & $\checkmark$ & & 3 & & & $\checkmark$ & & & & & $\checkmark$ & 2 & 5 \\
\hline
\end{tabular}

Fonte: Elaboração dos autores.

São apontadas nove explicações para a perceção de maior insucesso dos rapazes (Quadro 3). A causa mais apontada (cinco professores, dois homens e três mulheres) é que as raparigas são mais trabalhadoras, mais estudiosas, mais esforçadas do que os rapazes: "Menos empenho, nas aulas, os rapazes têm mais dificuldade em se concentrar, também são menos estudiosos, são menos regulares no estudo” (P5). 
Outras causas assinaladas para a desigualdade no sucesso de rapazes e raparigas são: a diferença de maturidade; o facto de os rapazes preferirem o trabalho prático, sendo a abordagem da disciplina de Biologia e Geologia muito teórica; as raparigas terem melhores competências de interpretação/análise; o facto de os rapazes pretenderem mais vezes concorrer a cursos em que BG não seja prova específica e, por isso, não dão tanta importância à disciplina; os critérios de avaliação interna que valorizam mais as provas escritas, em detrimento de outras competências mais atribuídas aos rapazes; a escola favorecer mais as atitudes e os comportamentos das raparigas; os rapazes sofrerem pressão pelos pares, havendo, por vezes, segregação dos rapazes estudiosos; e a necessidade que as raparigas sentem de fugir do papel de género, ainda hoje atribuído às mulheres.

\section{QUADRO 3 - Perceções dos professores sobre as causas do insucesso dos rapazes na disciplina de BG}

\begin{tabular}{|c|c|c|c|c|c|c|c|c|c|c|c|c|c|c|c|c|c|c|}
\hline \multirow[b]{2}{*}{$\begin{array}{l}\text { CAUSAS DO } \\
\text { INSUCESSO DOS } \\
\text { RAPAZES EM BG }\end{array}$} & \multicolumn{8}{|c|}{ HOMENS } & \multicolumn{9}{|c|}{ MULHERES } & \multirow[b]{2}{*}{$\stackrel{\frac{1}{6}}{\frac{5}{6}}$} \\
\hline & P1 & P2 & P3 & P4 & P5 & P6 & P7 & 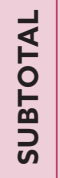 & P8 & P9 & P10 & P11 & P12 & P13 & P14 & P15 & 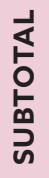 & \\
\hline $\begin{array}{l}\text { As raparigas trabalham } \\
\text { mais }\end{array}$ & & & & $\checkmark$ & $\checkmark$ & & & 2 & & $\checkmark$ & & $\checkmark$ & $\checkmark$ & & & & 3 & 5 \\
\hline $\begin{array}{l}\text { Os rapazes são mais } \\
\text { imaturos }\end{array}$ & $\checkmark$ & & & $\checkmark$ & & & & 2 & & & & & & $\checkmark$ & $\checkmark$ & & 2 & 4 \\
\hline $\begin{array}{l}\text { Os rapazes preferem o } \\
\text { trabalho prático }\end{array}$ & & & & & & & & 0 & $\checkmark$ & & & $\checkmark$ & & & & & 2 & 2 \\
\hline $\begin{array}{l}\text { As raparigas têm } \\
\text { melhores competências } \\
\text { de interpretação/análise }\end{array}$ & & & & & & & $\checkmark$ & 1 & & & & & & & & & 0 & 1 \\
\hline $\begin{array}{l}\text { Os rapazes pretendem } \\
\text { cursos em que BG não } \\
\text { seja específica }\end{array}$ & & & & & & & $\checkmark$ & 1 & & & & & & & & & 0 & 1 \\
\hline $\begin{array}{l}\text { Os critérios de avaliação } \\
\text { valorizam mais as provas } \\
\text { escritas }\end{array}$ & & & & & $\checkmark$ & & & 1 & & & & & & & & & 0 & 1 \\
\hline $\begin{array}{l}\text { A escola favorece } \\
\text { atitudes e } \\
\text { comportamentos } \\
\text { femininos }\end{array}$ & & & & & $\checkmark$ & & & 1 & & & & & & & & & 0 & 1 \\
\hline $\begin{array}{l}\text { Os rapazes sofrem } \\
\text { pressão pelos pares }\end{array}$ & & & & $\checkmark$ & & & & 1 & & & & & & & & & 0 & 1 \\
\hline $\begin{array}{l}\text { As raparigas fogem do } \\
\text { papel de género }\end{array}$ & & & & $\checkmark$ & & & & 1 & & & & & & & & & 0 & 1 \\
\hline
\end{tabular}

Fonte: Elaboração dos autores.

Embora mais professoras afirmem ter perceção de o insucesso ser maior entre os rapazes do que entre as raparigas, são claramente os professores que mais procuram as causas dessa diferença de desempenho, diversificando e aprofundando mais as explicações para a desvantagem dos rapazes. As professoras atribuem o 
insucesso deles apenas à falta de trabalho e de empenho e ao facto de os rapazes serem mais imaturos.

Perceções dos professores sobre as causas de insucesso no exame nacional de Biologia e Geologia

Os professores não têm dúvidas de que a principal causa de insucesso dos alunos no exame (Quadro 4) é o grau de complexidade da prova (11 professores, seis homens e cinco mulheres).

QUADRO 4 - Perceções dos professores sobre as causas de insucesso no exame de BG

\begin{tabular}{|c|c|c|c|c|c|c|c|c|c|c|c|c|c|c|c|c|c|c|}
\hline \multirow[b]{2}{*}{$\begin{array}{l}\text { CAUSAS DO } \\
\text { INSUCESSO NO EXAME } \\
\text { DE BG }\end{array}$} & \multicolumn{8}{|c|}{ HOMENS } & \multicolumn{9}{|c|}{ MULHERES } & \multirow[b]{2}{*}{$\begin{array}{l}\frac{1}{5} \\
\stackrel{5}{\circ}\end{array}$} \\
\hline & P1 & P2 & P3 & P4 & P5 & P6 & P7 & 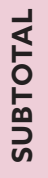 & P8 & P9 & P10 & P11 & P12 & P13 & P14 & P15 & 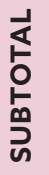 & \\
\hline $\begin{array}{l}\text { Elevado grau de } \\
\text { complexidade do exame }\end{array}$ & $\checkmark$ & $\checkmark$ & $\checkmark$ & $\checkmark$ & $\checkmark$ & $\checkmark$ & & 6 & $\checkmark$ & & $\checkmark$ & & $\checkmark$ & & $\checkmark$ & $\checkmark$ & 5 & 11 \\
\hline $\begin{array}{l}\text { Situação de stress/ } \\
\text { ansiedade }\end{array}$ & $\checkmark$ & $\checkmark$ & $\checkmark$ & $\checkmark$ & & & & 4 & & $\checkmark$ & $\checkmark$ & & $\checkmark$ & $\checkmark$ & $\checkmark$ & & 5 & 9 \\
\hline $\begin{array}{l}\text { Dificuldades de } \\
\text { leitura, interpretação e } \\
\text { comunicação }\end{array}$ & & $\checkmark$ & $\checkmark$ & & $\checkmark$ & $\checkmark$ & $\checkmark$ & 5 & & & $\checkmark$ & $\checkmark$ & $\checkmark$ & & & & 3 & 8 \\
\hline $\begin{array}{l}\text { Critérios de correção } \\
\text { e classificação } \\
\text { penalizadores }\end{array}$ & $\checkmark$ & & $\checkmark$ & $\checkmark$ & $\checkmark$ & $\checkmark$ & & 5 & & & & & & & $\checkmark$ & $\checkmark$ & 2 & 7 \\
\hline $\begin{array}{l}\text { Elevado grau de } \\
\text { complexidade da análise } \\
\text { documental }\end{array}$ & & $\checkmark$ & & $\checkmark$ & $\checkmark$ & & & 3 & & $\checkmark$ & & & $\checkmark$ & & $\checkmark$ & $\checkmark$ & 4 & 7 \\
\hline $\begin{array}{l}\text { Desfasamento entre } \\
\text { exame e programa }\end{array}$ & $\checkmark$ & & $\checkmark$ & $\checkmark$ & & & $\checkmark$ & 4 & $\checkmark$ & & & & $\checkmark$ & & & $\checkmark$ & 3 & 7 \\
\hline $\begin{array}{l}\text { Desadequação à } \\
\text { maturidade dos alunos }\end{array}$ & $\checkmark$ & & & $\checkmark$ & & & $\checkmark$ & 3 & & $\checkmark$ & & & $\checkmark$ & $\checkmark$ & $\checkmark$ & & 4 & 7 \\
\hline $\begin{array}{l}\text { Programa demasiado } \\
\text { extenso }\end{array}$ & & & & & $\checkmark$ & & & 1 & $\checkmark$ & & & $\checkmark$ & $\checkmark$ & $\checkmark$ & $\checkmark$ & & 5 & 6 \\
\hline $\begin{array}{l}\text { Falta de "treino" para o } \\
\text { exame }\end{array}$ & & & & & $\checkmark$ & & & 1 & & & & & & & & $\checkmark$ & 1 & 2 \\
\hline $\begin{array}{l}\text { Intervalo temporal entre } \\
\text { exames diminuto }\end{array}$ & & & & & $\checkmark$ & & & 1 & & & & & $\checkmark$ & & & & 1 & 2 \\
\hline $\begin{array}{l}\text { Falta de motivação para a } \\
\text { disciplina }\end{array}$ & & & & & & & & 0 & $\checkmark$ & & & & & & & & 1 & 1 \\
\hline $\begin{array}{l}\text { Não avaliação de todas } \\
\text { as competências }\end{array}$ & & & & & & $\checkmark$ & & 1 & & & & & & & & & 0 & 1 \\
\hline $\begin{array}{l}\text { Reduzida diversificação } \\
\text { de metodologias }\end{array}$ & & & & & & & & 0 & & & & $\checkmark$ & & & & & 1 & 1 \\
\hline $\begin{array}{l}\text { Falta de articulação } \\
\text { horizontal e vertical }\end{array}$ & & & & & $\checkmark$ & & & 1 & & & & & & & & & 0 & 1 \\
\hline
\end{tabular}

Fonte: Elaboração dos autores.

O facto de o exame ser uma situação de grande stress e ansiedade para os alunos é uma causa apontada por nove professores, quatro homens e cinco mulheres: "Os 
alunos vão para o exame logo com uma pressão muito maior do que era desejável, porque eles sabem que é um exame em que vão ter dificuldades” (P3).

Os docentes (oito professores, cinco homens e três mulheres) também afirmam que as dificuldades de leitura, interpretação, análise e comunicação, por parte dos alunos, estão na base do insucesso no exame. Referem ainda outras causas que, na realidade, são fatores que acrescentam dificuldade à prova nacional, tais como: os critérios de correção e classificação do exame muito penalizadores (sete professores, cinco homens e duas mulheres), o elevado grau de complexidade da análise documental (sete professores, três homens e quatro mulheres), o desfasamento entre o que é pedido no exame e o que é exigido pelo programa (sete professores, quatro homens e três mulheres) e a desadequação do exame à maturidade dos alunos (sete professores, três homens e quatro mulheres).

É ainda de salientar o facto de o programa da disciplina ser demasiado extenso, causa apontada por seis professores, um homem e cinco mulheres.

É notória a maior preocupação dos homens com as dificuldades dos alunos relacionadas à leitura, interpretação, análise e comunicação e aos critérios de correção e classificação do exame que consideram muito penalizadores, enquanto as mulheres, mais uma vez, referem mais como causa de insucesso o programa da disciplina demasiado extenso.

\section{Perceções dos professores sobre o insucesso no exame nacional de Biologia e} Geologia por sexo

Quando questionados sobre as suas perceções e experiências sobre o insucesso no exame nacional em função do sexo (Quadro 5), oito professores, sete homens e apenas uma mulher, percecionam diferenças, considerando que o insucesso é superior entre os rapazes. Sete docentes mulheres não percecionam diferenças e deixam transparecer que nunca pensaram nesse assunto: "Nunca me dei ao trabalho de fazer essa comparação. Para mim, são alunos, independentemente do sexo” (P13).

São apontadas nove explicações para o maior insucesso dos rapazes no exame, registadas no Quadro 6. Mais uma vez, a causa mais apontada (nove docentes, quatro homens e cinco mulheres) é que as raparigas são mais trabalhadoras, mais estudiosas, mais esforçadas do que os rapazes: "Naturalmente, em termos médios, as meninas trabalham mais na sala de aula, estão mais atentas, são mais colaborativas, participam mais, fazem quase sempre o trabalho de casa. Portanto, isso é fácil de explicar. São mais empenhadas” (P2). 
QUADRO 5 - Perceções dos professores sobre o insucesso no exame de BG, por sexo

\begin{tabular}{|c|c|c|c|c|c|c|c|c|c|c|c|c|c|c|c|c|c|c|}
\hline \multirow[b]{2}{*}{$\begin{array}{l}\text { INSUCESSO NO EXAME } \\
\text { POR SEXO }\end{array}$} & \multicolumn{8}{|c|}{ HOMENS } & \multicolumn{9}{|c|}{ MULHERES } & \multirow[b]{2}{*}{ 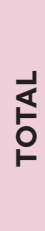 } \\
\hline & P1 & P2 & P3 & P4 & P5 & P6 & P7 & $\begin{array}{l}\frac{1}{5} \\
\frac{5}{0} \\
\frac{1}{2} \\
\stackrel{0}{n}\end{array}$ & P8 & P9 & P10 & P11 & P12 & P13 & P14 & P15 & 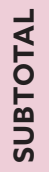 & \\
\hline $\begin{array}{l}\text { O insucesso é superior } \\
\text { entre as raparigas }\end{array}$ & & & & & & & & 0 & & & & & & & & & 0 & 0 \\
\hline $\begin{array}{l}\text { O insucesso é superior } \\
\text { entre os rapazes }\end{array}$ & $\checkmark$ & $\checkmark$ & $\checkmark$ & $\checkmark$ & $\checkmark$ & $\checkmark$ & $\checkmark$ & 7 & $\checkmark$ & & & & & & & & 1 & 8 \\
\hline $\begin{array}{l}\text { Não perceciona } \\
\text { diferenças }\end{array}$ & & & & & & & & 0 & & $\checkmark$ & $\checkmark$ & $\checkmark$ & $\checkmark$ & $\checkmark$ & $\checkmark$ & $\checkmark$ & 7 & 7 \\
\hline
\end{tabular}

Fonte: Elaboração dos autores.

\section{QUADRO 6 - Perceções dos professores sobre as causas do insucesso dos rapazes no exame de BG}

\begin{tabular}{|c|c|c|c|c|c|c|c|c|c|c|c|c|c|c|c|c|c|c|}
\hline \multirow[b]{2}{*}{$\begin{array}{l}\text { CAUSAS DO } \\
\text { INSUCESSO DOS } \\
\text { RAPAZES NO EXAME } \\
\text { DE BG }\end{array}$} & \multicolumn{8}{|c|}{ HOMENS } & \multicolumn{9}{|c|}{ MULHERES } & \multirow[b]{2}{*}{$\frac{\text { L }}{\stackrel{5}{\circ}}$} \\
\hline & P1 & P2 & P3 & P4 & P5 & P6 & P7 & $\begin{array}{l}\frac{1}{5} \\
\frac{5}{0} \\
\frac{1}{0} \\
\frac{0}{2}\end{array}$ & P8 & P9 & P10 & P11 & P12 & P13 & P14 & P15 & 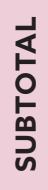 & \\
\hline $\begin{array}{l}\text { As raparigas trabalham } \\
\text { mais }\end{array}$ & & $\checkmark$ & $\checkmark$ & $\checkmark$ & $\checkmark$ & & & 4 & $\checkmark$ & $\checkmark$ & & & $\checkmark$ & $\checkmark$ & & $\checkmark$ & 5 & 9 \\
\hline $\begin{array}{l}\text { Os rapazes são mais } \\
\text { imaturos }\end{array}$ & $\checkmark$ & $\checkmark$ & & $\checkmark$ & & & & 3 & & & & & & & $\checkmark$ & & 1 & 4 \\
\hline $\begin{array}{l}\text { Está relacionado aos } \\
\text { papéis sociais de género }\end{array}$ & & $\checkmark$ & & $\checkmark$ & $\checkmark$ & & & 3 & $\checkmark$ & & & & & & & & 1 & 4 \\
\hline $\begin{array}{l}\text { As raparigas são mais } \\
\text { organizadas }\end{array}$ & & & & & & $\checkmark$ & & 1 & & & & & & $\checkmark$ & & $\checkmark$ & 2 & 3 \\
\hline $\begin{array}{l}\text { Os rapazes pretendem } \\
\text { cursos em que BG não } \\
\text { seja específica }\end{array}$ & & & & & & $\checkmark$ & $\checkmark$ & 2 & & & & & & & & & 0 & 2 \\
\hline $\begin{array}{l}\text { As raparigas são mais } \\
\text { ansiosas, e os rapazes } \\
\text { são mais relaxados }\end{array}$ & & & & & & & & 0 & & $\checkmark$ & & & $\checkmark$ & & & & 2 & 2 \\
\hline $\begin{array}{l}\text { Os rapazes têm outras } \\
\text { atividades extraescola }\end{array}$ & & & & & & & & 0 & & $\checkmark$ & & & & & & & 1 & 1 \\
\hline $\begin{array}{l}\text { A abordagem teórica da } \\
\text { disciplina favorece as } \\
\text { raparigas }\end{array}$ & & & & & & & & 0 & $\checkmark$ & & & & & & & & 1 & 1 \\
\hline $\begin{array}{l}\text { A escola favorece } \\
\text { atitudes e } \\
\text { comportamentos } \\
\text { femininos }\end{array}$ & & & & & $\checkmark$ & & & 1 & & & & & & & & & 0 & 1 \\
\hline
\end{tabular}

Fonte: Elaboração dos autores.

Outras opiniões são de que essa diferença está relacionada ao facto de os rapazes serem mais imaturos do que as raparigas; aos papéis sociais de género; à maior organização das raparigas; ao facto de os rapazes pretenderem cursos em que o exame de Biologia e Geologia não seja prova de acesso; às raparigas serem mais ansiosas e aos 
rapazes serem mais relaxados, acabando por descurar o estudo; ao facto de os rapazes gastarem muito tempo noutras atividades extraescola, tais como o futebol e os jogos digitais, sobrando menos tempo para se dedicarem ao estudo; à abordagem teórica da disciplina; e ao facto de a escola favorecer atitudes e comportamentos femininos.

São claramente os homens que mais percecionam o maior insucesso dos rapazes no exame, embora o atribuam sobretudo à falta de trabalho e de empenho e ao facto de os rapazes serem mais imaturos, ou seja, mais uma vez, referem principalmente causas relacionadas aos próprios alunos. No entanto, são os docentes homens que mais referem o problema dos papeis de género atribuídos pela sociedade a rapazes e raparigas. É interessante perceber que as docentes mulheres não refletem sobre o problema desse ponto de vista.

\section{Influência da realização do exame nacional nas práticas pedagógicas dos professores}

A totalidade dos docentes declarou que a existência do exame nacional afeta as suas práticas pedagógicas. No Quadro 7, apresentam-se os efeitos da influência da realização do exame nacional nas práticas pedagógicas dos docentes.

A maioria dos professores, 12, sendo cinco homens e sete mulheres, afirmam estar preocupados em aplicar métodos de ensino orientados para o sucesso no exame - "Treina-se muito para o exame" (P15) -, estando a disciplina "[...] claramente transformada na preparação para exame" (P7). Um outro efeito apontado por oito professores, três homens e cinco mulheres, é a menor diversificação das metodologias que implantam na sala de aula, recorrendo a aulas mais expositivas, reconhecendo o empobrecimento das aulas.

\section{QUADRO 7 - Efeitos da realização do exame nacional nas práticas pedagógicas dos professores}

\begin{tabular}{|c|c|c|c|c|c|c|c|c|c|c|c|c|c|c|c|c|c|c|}
\hline \multirow{2}{*}{$\begin{array}{l}\text { INFLUÊNCIA DO } \\
\text { EXAME NACIONAL } \\
\text { NAS PRÁTICAS } \\
\text { PEDAGÓGICAS DOS } \\
\text { PROFESSORES }\end{array}$} & \multicolumn{8}{|c|}{ HOMENS } & \multicolumn{9}{|c|}{ MULHERES } & \multirow[b]{2}{*}{$\frac{\frac{1}{4}}{\frac{6}{6}}$} \\
\hline & P1 & $\mathbf{P 2}$ & P3 & P4 & P5 & P6 & P7 & 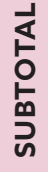 & P8 & P9 & P10 & P11 & P12 & P13 & P14 & P15 & $\begin{array}{l}\frac{1}{5} \\
\frac{1}{0} \\
\frac{1}{0} \\
\frac{0}{2}\end{array}$ & \\
\hline $\begin{array}{l}\text { Aplicação de métodos de } \\
\text { ensino orientados para o } \\
\text { sucesso no exame }\end{array}$ & $\checkmark$ & $\checkmark$ & $\checkmark$ & $\checkmark$ & & & $\checkmark$ & 5 & $\checkmark$ & $\checkmark$ & $\checkmark$ & & $\checkmark$ & $\checkmark$ & $\checkmark$ & $\checkmark$ & 7 & 12 \\
\hline $\begin{array}{l}\text { Menor diversificação de } \\
\text { metodologias }\end{array}$ & $\checkmark$ & & & & $\checkmark$ & & $\checkmark$ & 3 & & $\checkmark$ & $\checkmark$ & $\checkmark$ & & $\checkmark$ & & $\checkmark$ & 5 & 8 \\
\hline $\begin{array}{l}\text { Maior preocupação em } \\
\text { cumprir o programa }\end{array}$ & & & & & $\checkmark$ & & $\checkmark$ & 2 & $\checkmark$ & $\checkmark$ & $\checkmark$ & & & $\checkmark$ & & & 4 & 6 \\
\hline $\begin{array}{l}\text { Abandono dos } \\
\text { momentos de ensino } \\
\text { individualizado }\end{array}$ & & & & & & $\checkmark$ & & 1 & & & & & & $\checkmark$ & & & 1 & 2 \\
\hline
\end{tabular}

Fonte: Elaboração dos autores. 
É notório pelo discurso dos professores e professoras que uma das metodologias mais afetadas com a pressão do exame é o trabalho laboratorial, que acabam por não pôr em prática por não ser valorizado no exame. Os docentes referem ainda ter grande preocupação em cumprir o programa, mesmo pensando que isso possa representar um prejuízo para os alunos por não conseguir proporcionar momentos de ensino individualizado.

As professoras mostram-se mais preocupadas pela influência que a existência do exame exerce nas suas práticas, ou talvez tenham maior consciência dessa influência.

\section{Influência da realização do exame nacional nas práticas de avaliação dos professores}

Relativamente à influência da realização do exame nacional nas práticas de avaliação, também a totalidade dos professores reconheceu esse efeito, que se manifesta de formas diferentes (Quadro 8).

\section{QUADRO 8 - Efeitos da realização do exame nacional nas práticas de avaliação dos professores}

\begin{tabular}{|c|c|c|c|c|c|c|c|c|c|c|c|c|c|c|c|c|c|c|}
\hline \multirow[b]{2}{*}{$\begin{array}{l}\text { INFLUÊNCIA DO } \\
\text { EXAME NACIONAL } \\
\text { NAS PRÁTICAS DE } \\
\text { AVALIAÇÃO DOS } \\
\text { PROFESSORES }\end{array}$} & \multicolumn{8}{|c|}{ HOMENS } & \multicolumn{9}{|c|}{ MULHERES } & \multirow[b]{2}{*}{ 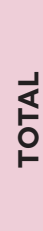 } \\
\hline & P1 & P2 & P3 & P4 & P5 & P6 & P7 & $\begin{array}{l}\frac{1}{5} \\
\frac{0}{0} \\
\frac{1}{2} \\
\text { un }\end{array}$ & P8 & P9 & P10 & P11 & P12 & P13 & P14 & P15 & 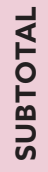 & \\
\hline $\begin{array}{l}\text { Estrutura dos testes } \\
\text { semelhante à dos } \\
\text { exames }\end{array}$ & $\checkmark$ & $\checkmark$ & $\checkmark$ & $\checkmark$ & $\checkmark$ & $\checkmark$ & $\checkmark$ & 7 & $\checkmark$ & $\checkmark$ & $\checkmark$ & $\checkmark$ & $\checkmark$ & $\checkmark$ & $\checkmark$ & $\checkmark$ & 8 & 15 \\
\hline $\begin{array}{l}\text { Critérios de correção/ } \\
\text { classificação dos testes } \\
\text { semelhantes aos dos } \\
\text { exames }\end{array}$ & $\checkmark$ & $\checkmark$ & & $\checkmark$ & $\checkmark$ & $\checkmark$ & $\checkmark$ & 6 & $\checkmark$ & $\checkmark$ & $\checkmark$ & $\checkmark$ & $\checkmark$ & $\checkmark$ & $\checkmark$ & $\checkmark$ & 8 & 14 \\
\hline $\begin{array}{l}\text { Utilização de testes } \\
\text { iguais para todas as } \\
\text { turmas }\end{array}$ & & & & & & $\checkmark$ & & 1 & $\checkmark$ & & & & & & & & 1 & 2 \\
\hline $\begin{array}{l}\text { Menor diversificação } \\
\text { dos instrumentos de } \\
\text { avaliação }\end{array}$ & & & & & $\checkmark$ & & & 1 & & & & $\checkmark$ & & & & & 1 & 2 \\
\hline Influência na nota interna & & & $\checkmark$ & & & & & 1 & $\checkmark$ & & & & & & & & 1 & 2 \\
\hline
\end{tabular}

Fonte: Elaboração dos autores.

Todos os professores adotaram nos testes uma estrutura semelhante aos exames para familiarizar os alunos com o tipo de prova. E a quase totalidade dos docentes adota critérios de correção e de classificação também semelhantes aos do exame. Referem ainda o facto de diversificarem menos os instrumentos de avaliação, privilegiando a prova escrita como instrumento quase único de avaliação, e a influência da realização do exame na hora de atribuir a nota interna e o quanto lhes é difícil não pensar no desempenho que o aluno terá no exame. 
Nesta questão, não se apuram diferenças entre as respostas de professores e professoras.

\section{Opinião dos professores sobre as características gerais do exame}

De uma forma geral, os docentes consideram o exame de elevado grau de dificuldade para os alunos por motivos variados (Quadro 9): elevado grau de exigência cognitiva, linguagem complexa, elevado grau de complexidade da análise documental, questões pouco claras e critérios de correção e classificação do exame muito penalizadores. Pensam também que o exame está desadequado à maturidade dos alunos. Há ainda dois professores do sexo masculino que referem o facto de o exame não avaliar todas as competências que se supõe serem trabalhadas.

\section{QUADRO 9 - Opinião dos professores sobre as características gerais do exame}

\begin{tabular}{|c|c|c|c|c|c|c|c|c|c|c|c|c|c|c|c|c|c|c|}
\hline \multirow[b]{2}{*}{$\begin{array}{l}\text { CARACTERÍSTICAS } \\
\text { GERAIS DO EXAME }\end{array}$} & \multicolumn{8}{|c|}{ HOMENS } & \multicolumn{9}{|c|}{ MULHERES } & \multirow[b]{2}{*}{$\begin{array}{l}\frac{1}{\leftarrow} \\
\stackrel{5}{\circ}\end{array}$} \\
\hline & P1 & $\mathbf{P 2}$ & P3 & P4 & P5 & P6 & P7 & 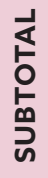 & P8 & P9 & P10 & P11 & P12 & P13 & P14 & P15 & $\begin{array}{l}\frac{1}{5} \\
\frac{5}{\circ} \\
\frac{1}{9} \\
\stackrel{0}{n}\end{array}$ & \\
\hline O exame é difícil & $\checkmark$ & & $\checkmark$ & $\checkmark$ & $\checkmark$ & $\checkmark$ & $\checkmark$ & 6 & $\checkmark$ & & $\checkmark$ & $\checkmark$ & $\checkmark$ & $\checkmark$ & $\checkmark$ & $\checkmark$ & 7 & 13 \\
\hline O exame é desadequado & $\checkmark$ & $\checkmark$ & & $\checkmark$ & $\checkmark$ & $\checkmark$ & $\checkmark$ & 6 & $\checkmark$ & & & $\checkmark$ & $\checkmark$ & & & $\checkmark$ & 4 & 10 \\
\hline $\begin{array}{l}\text { O exame não avalia todas } \\
\text { as competências }\end{array}$ & & & & & $\checkmark$ & $\checkmark$ & & 2 & & & & & & & & & 0 & 2 \\
\hline O exame não é difícil & & & & & & & & 0 & & $\checkmark$ & & & & & & & 1 & 1 \\
\hline
\end{tabular}

Fonte: Elaboração dos autores.

\section{Opinião dos professores sobre a quantidade e qualidade dos conteúdos} avaliados no exame

Quanto aos conteúdos (Quadro 10), dez docentes, quatro homens e seis mulheres, declararam que a quantidade é desadequada por ser demasiada.

No que diz respeito à qualidade, a maioria dos docentes considera-a desadequada, embora apresentem razões diferentes: o exame avalia uma amostra não representativa dos conteúdos lecionados, os conteúdos abordados extrapolam o programa, e os conteúdos são abordados com um grau de dificuldade demasiado elevado para o que o programa da disciplina aconselha.

Mais uma vez, nessa questão, verifica-se uma tendência maior de as mulheres se preocuparem com a extensão do programa. 
QUADRO 10 - Opinião dos professores sobre a quantidade e qualidade dos conteúdos avaliados no exame

\begin{tabular}{|c|c|c|c|c|c|c|c|c|c|c|c|c|c|c|c|c|c|c|c|}
\hline \multirow{2}{*}{\multicolumn{2}{|c|}{$\begin{array}{l}\text { QUANTIDADE E } \\
\text { QUALIDADE DOS } \\
\text { CONTEÚDOS } \\
\text { AVALIADOS NO EXAME }\end{array}$}} & \multicolumn{8}{|c|}{ HOMENS } & \multicolumn{9}{|c|}{ MULHERES } & \multirow[b]{2}{*}{$\begin{array}{l}\vec{\leftarrow} \\
\stackrel{5}{\circ} \\
\vdash\end{array}$} \\
\hline & & P1 & P2 & P3 & P4 & P5 & P6 & P7 & 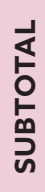 & P8 & P9 & P10 & P11 & P12 & P13 & P14 & P15 & 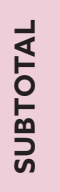 & \\
\hline \multicolumn{2}{|c|}{$\begin{array}{l}\text { Quantidade } \\
\text { desadequada por ser } \\
\text { demasiada }\end{array}$} & & $\checkmark$ & & $\checkmark$ & $\checkmark$ & $\checkmark$ & & 4 & & $\checkmark$ & $\checkmark$ & $\checkmark$ & & $\checkmark$ & $\checkmark$ & $\checkmark$ & 6 & 10 \\
\hline \multirow{3}{*}{ 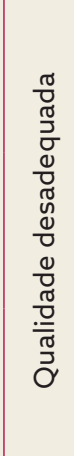 } & $\begin{array}{l}\text { Avalia uma } \\
\text { amostra de } \\
\text { conteúdos não } \\
\text { representativa }\end{array}$ & & $\checkmark$ & & $\checkmark$ & & & & 2 & & $\checkmark$ & & & $\checkmark$ & $\checkmark$ & $\checkmark$ & & 4 & 6 \\
\hline & \begin{tabular}{|l|} 
Aborda conteúdos/ \\
conceitos não \\
incluídos no \\
programa
\end{tabular} & $\checkmark$ & & & & & & $\checkmark$ & 2 & $\checkmark$ & & & & $\checkmark$ & & & & 2 & 4 \\
\hline & $\begin{array}{l}\text { Aborda os } \\
\text { conteúdos com } \\
\text { elevado grau de } \\
\text { dificuldade }\end{array}$ & & $\checkmark$ & $\checkmark$ & & & & & 2 & $\checkmark$ & & & & & & & $\checkmark$ & 2 & 4 \\
\hline
\end{tabular}

Fonte: Elaboração dos autores.

Opinião dos professores sobre o tempo de realização do exame

Apenas um professor considerou que o tempo de realização do exame é desadequado (Quadro 11) por ser reduzido. Todos os outros o consideraram adequado.

QUADRO 11 - Opinião dos professores sobre o tempo de realização do exame

\begin{tabular}{|c|c|c|c|c|c|c|c|c|c|c|c|c|c|c|c|c|c|c|}
\hline \multirow[b]{2}{*}{$\begin{array}{l}\text { TEMPO DE } \\
\text { REALIZAÇÃO DO } \\
\text { EXAME }\end{array}$} & \multicolumn{8}{|c|}{ HOMENS } & & \multicolumn{8}{|c|}{ MULHERES } & \multirow[b]{2}{*}{$\begin{array}{l}\frac{1}{6} \\
\stackrel{\circ}{\circ}\end{array}$} \\
\hline & P1 & P2 & P3 & P4 & P5 & P6 & P7 & $\begin{array}{l}\frac{1}{5} \\
\frac{5}{0} \\
\frac{1}{9} \\
\frac{0}{n}\end{array}$ & P8 & P9 & P10 & P11 & P12 & P13 & P14 & P15 & $\begin{array}{l}\frac{1}{5} \\
\frac{5}{0} \\
\frac{1}{0} \\
\frac{0}{n}\end{array}$ & \\
\hline Adequado & $\checkmark$ & & $\checkmark$ & $\checkmark$ & $\checkmark$ & $\checkmark$ & $\checkmark$ & 6 & $\checkmark$ & $\checkmark$ & $\checkmark$ & $\checkmark$ & $\checkmark$ & $\checkmark$ & $\checkmark$ & $\checkmark$ & 8 & 14 \\
\hline $\begin{array}{l}\text { Desadequado por ser } \\
\text { reduzido }\end{array}$ & & $\checkmark$ & & & & & & 1 & & & & & & & & & 0 & 1 \\
\hline
\end{tabular}

Fonte: Elaboração dos autores.

Opinião dos professores sobre a linguagem usada nas questões incluídas no exame

Os docentes consideraram a linguagem usada nas questões do exame (Quadro 12) desadequada por ser de difícil compreensão para os alunos, não só no que diz respeito ao domínio da língua portuguesa, mas também quanto à linguagem científica. 
QUADRO 12 - Opinião dos professores sobre a linguagem usada nas questões do exame

\begin{tabular}{|c|c|c|c|c|c|c|c|c|c|c|c|c|c|c|c|c|c|c|}
\hline \multirow[b]{2}{*}{$\begin{array}{l}\text { LINGUAGEM USADA } \\
\text { NAS QUESTÕES DE } \\
\text { EXAME }\end{array}$} & \multicolumn{8}{|c|}{ HOMENS } & & \multicolumn{8}{|c|}{ MULHERES } & \multirow[b]{2}{*}{$\begin{array}{l}\stackrel{+}{\leftarrow} \\
\stackrel{\circ}{\circ}\end{array}$} \\
\hline & P1 & $\mathbf{P 2}$ & P3 & P4 & P5 & P6 & P7 & 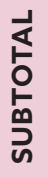 & P8 & P9 & P10 & P11 & P12 & P13 & P14 & P15 & $\begin{array}{l}\frac{1}{5} \\
\frac{5}{0} \\
\frac{1}{0} \\
\frac{0}{2}\end{array}$ & \\
\hline $\begin{array}{l}\text { Desadequada/de difícil } \\
\text { compreensão }\end{array}$ & $\checkmark$ & $\checkmark$ & $\checkmark$ & $\checkmark$ & $\checkmark$ & & $\checkmark$ & 6 & $\checkmark$ & $\checkmark$ & & $\checkmark$ & $\checkmark$ & $\checkmark$ & & $\checkmark$ & 6 & 12 \\
\hline Adequada/acessível & & & & & & $\checkmark$ & & 1 & & & $\checkmark$ & & & & $\checkmark$ & & 2 & 3 \\
\hline
\end{tabular}

Fonte: Elaboração dos autores.

\section{Opinião dos professores sobre o tipo e qualidade das questões do exame}

No Quadro 13, estão registadas as apreciações dos docentes quanto ao tipo e qualidade das questões incluídas no exame. Seis professores, dois homens e quatro mulheres, consideram adequado o género e a diversidade de perguntas que surgem nos exames.

\section{QUADRO 13 - Opinião dos professores sobre tipo e qualidade das questões do exame}

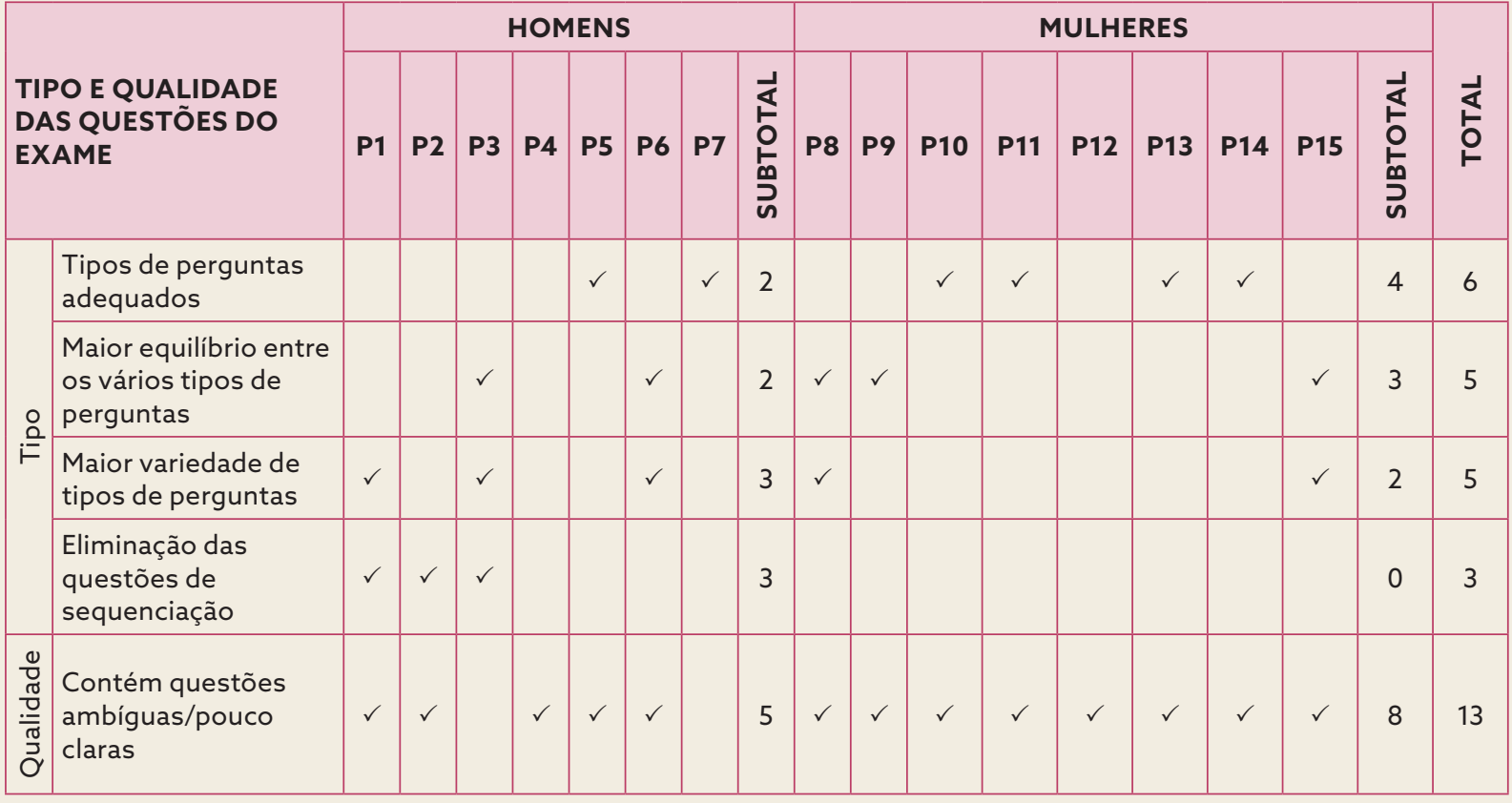

Fonte: Elaboração dos autores.

Os restantes professores entrevistados sugerem algumas mudanças, tais como: um maior equilíbrio dos vários tipos de questões, considerando que há um número exagerado de questões de escolha múltipla, e maior variedade de questões, sugerindo a introdução de questões de resposta curta e a eliminação das questões de sequenciação.

Já no que diz respeito à qualidade das questões, de uma forma geral, os professores consideram que os exames incluem questões pouco claras e ambíguas. 
Os homens estão menos satisfeitos do que as mulheres com os tipos de questões do exame e, por isso, fazem mais sugestões de mudança. No entanto, as mulheres fazem maior referência à falta de clareza das questões.

Opinião dos professores sobre o facto de o exame incluir questões centradas na análise de documentos e fontes de informação

De uma forma geral, os professores e professoras consideraram que os documentos e fontes de informação, como textos, figuras, esquemas, gráficos, devem constar do exame e que é importante desenvolver nos alunos as competências relacionadas à sua análise. Não obstante essa opinião, consideram-nos de difícil interpretação para os alunos, dificultando a resposta às questões (Quadro 14).

\section{QUADRO 14 - Opinião dos professores sobre a qualidade dos documentos/fontes de informação}

\begin{tabular}{|c|c|c|c|c|c|c|c|c|c|c|c|c|c|c|c|c|c|c|}
\hline \multirow[b]{2}{*}{$\begin{array}{l}\text { QUALIDADE DOS } \\
\text { DOCUMENTOS/ } \\
\text { FONTES DE } \\
\text { INFORMAÇÃO }\end{array}$} & \multicolumn{8}{|c|}{ HOMENS } & & \multicolumn{8}{|c|}{ MULHERES } & \multirow[b]{2}{*}{ 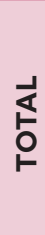 } \\
\hline & P1 & P2 & P3 & P4 & P5 & P6 & P7 & $\begin{array}{l}\frac{1}{5} \\
\frac{5}{0} \\
\frac{1}{9} \\
\frac{0}{n}\end{array}$ & P8 & P9 & P10 & P11 & P12 & P13 & P14 & P15 & 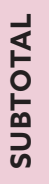 & \\
\hline Adequados & & & & & & & & 0 & & & & & & & $\checkmark$ & & 1 & 1 \\
\hline $\begin{array}{l}\text { De difícil interpretação } \\
\text { para os alunos }\end{array}$ & $\checkmark$ & $\checkmark$ & $\checkmark$ & $\checkmark$ & $\checkmark$ & $\checkmark$ & $\checkmark$ & 7 & $\checkmark$ & $\checkmark$ & $\checkmark$ & $\checkmark$ & $\checkmark$ & $\checkmark$ & & $\checkmark$ & 7 & 14 \\
\hline $\begin{array}{l}\text { Presentes em demasiado } \\
\text { número }\end{array}$ & & & & & & & & 0 & & & & & & & & $\checkmark$ & 1 & 1 \\
\hline
\end{tabular}

Fonte: Elaboração dos autores.

\section{Opinião dos professores sobre os critérios de correção aplicados nos exames}

Os docentes entrevistados têm uma opinião muito negativa acerca dos critérios de correção e classificação aplicados nos exames (Quadro 15), sendo que nenhum professor os considerou justos. Todos os professores os consideram penalizadores, demasiado rígidos e até injustos.

Apenas duas professoras pensam que os critérios eliminam a subjetividade da correção, os restantes são de opinião de que há subjetividade inerente à correção do exame. É importante realçar que, do discurso dos professores e professoras, ressalta-se um desconforto muito grande na aplicação dos critérios de correção e de classificação dos exames por não concordarem com eles e considerarem que são obrigados a penalizar os alunos. 


\section{QUADRO 15 - Opinião dos professores sobre os critérios de correção aplicados nos exames}

\begin{tabular}{|c|c|c|c|c|c|c|c|c|c|c|c|c|c|c|c|c|c|c|}
\hline \multirow[b]{2}{*}{$\begin{array}{l}\text { CRITÉRIOS DE } \\
\text { CORREÇÃO } \\
\text { APLICADOS NOS } \\
\text { EXAMES }\end{array}$} & \multicolumn{8}{|c|}{ HOMENS } & & \multicolumn{8}{|c|}{ MULHERES } & \multirow[b]{2}{*}{ 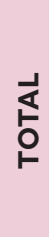 } \\
\hline & P1 & P2 & P3 & P4 & P5 & P6 & P7 & 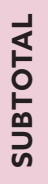 & P8 & P9 & P10 & P11 & P12 & P13 & P14 & P15 & $\begin{array}{l}\frac{1}{5} \\
\frac{1}{0} \\
\frac{1}{\infty} \\
\end{array}$ & \\
\hline $\begin{array}{l}\text { Penalizadores/ } \\
\text { demasiado rígidos }\end{array}$ & $\checkmark$ & $\checkmark$ & $\checkmark$ & $\checkmark$ & $\checkmark$ & $\checkmark$ & $\checkmark$ & 7 & $\checkmark$ & $\checkmark$ & $\checkmark$ & $\checkmark$ & $\checkmark$ & $\checkmark$ & $\checkmark$ & $\checkmark$ & 8 & 15 \\
\hline $\begin{array}{l}\text { Não eliminam a } \\
\text { subjetividade }\end{array}$ & & $\checkmark$ & & $\checkmark$ & & $\checkmark$ & $\checkmark$ & 4 & $\checkmark$ & $\checkmark$ & & $\checkmark$ & $\checkmark$ & $\checkmark$ & $\checkmark$ & & 6 & 10 \\
\hline Eliminam a subjetividade & & & & & & & & 0 & & & $\checkmark$ & & & & & $\checkmark$ & 2 & 2 \\
\hline
\end{tabular}

Fonte: Elaboração dos autores.

Medidas sugeridas pelos professores para promover o sucesso na disciplina de Biologia e Geologia

Os professores sugerem 19 medidas para promover o sucesso na disciplina de Biologia e Geologia (Quadro 16).

A medida mais relevante é a diminuição, revisão e atualização do programa da disciplina (11 professores, cinco homens e seis mulheres): "Alterar o programa. Isso é a primeira coisa. Diminuir obrigatoriamente. Mas também fazer um estudo aprofundado do que é mais importante na Biologia e Geologia. Porque um programa que tem 20 anos, mais ou menos, não pode estar atualizado” (P4). Sugerem ainda: maior diversificação de metodologias de ensino nas suas aulas que, no entanto, dizem ser difícil sem a diminuição do programa; aumento da componente prática/laboratorial; divisão da disciplina em duas, separando a Biologia da Geologia; ensino mais individualizado; mais e melhor formação para professores. Com menor frequência, indicam: eliminação do exame da disciplina, diminuição do número de alunos por turma, diminuição do número de disciplinas ou da carga horária semanal e a criação de outra disciplina de opção para os alunos que não pretendam seguir estudos superiores relacionados às áreas da Biologia e da Geologia.

Não se percecionam nesta questão diferenças relevantes entres as respostas dos professores e das professoras, embora apenas os docentes do sexo masculino refiram a necessidade de formação e a diminuição do número de alunos por turma. 
QUADRO 16 - Medidas sugeridas pelos professores para promover o sucesso na disciplina de BG

\begin{tabular}{|c|c|c|c|c|c|c|c|c|c|c|c|c|c|c|c|c|c|c|}
\hline \multirow[b]{2}{*}{$\begin{array}{l}\text { MEDIDAS } \\
\text { PROMOTORAS DE } \\
\text { SUCESSO EM BG }\end{array}$} & \multicolumn{8}{|c|}{ HOMENS } & \multicolumn{9}{|c|}{ MULHERES } & \multirow[b]{2}{*}{$\frac{1}{\frac{1}{5}}$} \\
\hline & P1 & P2 & P3 & P4 & P5 & P6 & P7 & 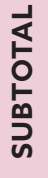 & P8 & P9 & P10 & P11 & P12 & P13 & P14 & P15 & $\begin{array}{l}\frac{1}{<} \\
\frac{1}{0} \\
\frac{1}{\infty} \\
\text { n } \\
\text { n }\end{array}$ & \\
\hline $\begin{array}{l}\text { Diminuição/revisão do } \\
\text { programa }\end{array}$ & $\checkmark$ & $\checkmark$ & & $\checkmark$ & & $\checkmark$ & $\checkmark$ & 5 & $\checkmark$ & $\checkmark$ & & & $\checkmark$ & $\checkmark$ & $\checkmark$ & $\checkmark$ & 6 & 11 \\
\hline $\begin{array}{l}\text { Diversificação de } \\
\text { metodologias de ensino }\end{array}$ & & & & $\checkmark$ & $\checkmark$ & $\checkmark$ & & 3 & & & & & & $\checkmark$ & & $\checkmark$ & 2 & 5 \\
\hline $\begin{array}{l}\text { Aumento da componente } \\
\text { prática/laboratorial }\end{array}$ & & $\checkmark$ & & & & $\checkmark$ & & 2 & $\checkmark$ & & $\checkmark$ & & & & & & 2 & 4 \\
\hline $\begin{array}{l}\text { Divisão em duas } \\
\text { disciplinas: Biologia e } \\
\text { Geologia }\end{array}$ & & & & & & $\checkmark$ & & 1 & & & $\checkmark$ & & & & $\checkmark$ & & 2 & 3 \\
\hline $\begin{array}{l}\text { Ensino mais } \\
\text { individualizado }\end{array}$ & & & $\checkmark$ & & & & & 1 & & & & & $\checkmark$ & $\checkmark$ & & & 2 & 3 \\
\hline $\begin{array}{l}\text { Formação para } \\
\text { professores }\end{array}$ & $\checkmark$ & & & $\checkmark$ & $\checkmark$ & & & 3 & & & & & & & & & 0 & 3 \\
\hline Eliminação do exame & & & $\checkmark$ & & & & & 1 & & & & $\checkmark$ & & & & & 1 & 2 \\
\hline $\begin{array}{l}\text { Diminuição do } n^{\circ} \text { de } \\
\text { alunos por turma }\end{array}$ & & $\checkmark$ & & & & $\checkmark$ & & 2 & & & & & & & & & 0 & 2 \\
\hline $\begin{array}{l}\text { Diminuição do } n^{\circ} \text { de } \\
\text { disciplinas/carga horária }\end{array}$ & $\checkmark$ & & & & & & & 1 & & $\checkmark$ & & & & & & & 1 & 2 \\
\hline $\begin{array}{l}\text { Criação de outra } \\
\text { disciplina de opção }\end{array}$ & & & & & & & $\checkmark$ & 1 & & & & & & & & $\checkmark$ & 1 & 2 \\
\hline $\begin{array}{l}\text { Maior ênfase na avaliação } \\
\text { formativa }\end{array}$ & & & & & & $\checkmark$ & & 1 & & & & & & & & & 0 & 1 \\
\hline $\begin{array}{l}\text { Trabalho colaborativo } \\
\text { entre professores }\end{array}$ & & & & & $\checkmark$ & & & 1 & & & & & & & & & 0 & 1 \\
\hline $\begin{array}{l}\text { Disciplina no } 11^{\circ} \text { e } 12^{\circ} \\
\text { anos }\end{array}$ & & & & & & & & 0 & & & & & & & $\checkmark$ & & 1 & 1 \\
\hline $\begin{array}{l}\text { Alteração das } \\
\text { características do exame }\end{array}$ & & & & & & & & 0 & & & & & $\checkmark$ & & & & 1 & 1 \\
\hline $\begin{array}{l}\text { Trabalho de } \\
\text { competências de } \\
\text { leitura, interpretação e } \\
\text { comunicação }\end{array}$ & & & & & & & & 0 & & & $\checkmark$ & & & & & & 1 & 1 \\
\hline $\begin{array}{l}\text { Aumento da carga } \\
\text { horária da disciplina }\end{array}$ & & & & & & & & 0 & $\checkmark$ & & & & & & & & 1 & 1 \\
\hline $\begin{array}{l}\text { Elevação do grau de } \\
\text { dificuldade do ensino } \\
\text { básico }\end{array}$ & & $\checkmark$ & & & & & & 1 & & & & & & & & & 0 & 1 \\
\hline $\begin{array}{l}\text { Apoio psicopedagógico } \\
\text { para alunos/famílias }\end{array}$ & $\checkmark$ & & & & & & & 1 & & & & & & & & & 0 & 1 \\
\hline $\begin{array}{l}\text { Articulação do programa } \\
\text { da disciplina com outras }\end{array}$ & $\checkmark$ & & & & & & & 1 & & & & & & & & & 0 & 1 \\
\hline
\end{tabular}

Fonte: Elaboração dos autores. 
Medidas sugeridas pelos professores para promover o sucesso no exame nacional de Biologia e Geologia

Os professores propõem 23 medidas promotoras de sucesso dos alunos no exame de Biologia e Geologia (Quadro 17).

QUADRO 17 - Medidas sugeridas pelos professores para promover o sucesso no exame de BG

\begin{tabular}{|c|c|c|c|c|c|c|c|c|c|c|c|c|c|c|c|c|c|c|}
\hline \multirow[b]{2}{*}{$\begin{array}{l}\text { MEDIDAS } \\
\text { PROMOTORAS DE } \\
\text { SUCESSO NO EXAME } \\
\text { DE BG }\end{array}$} & \multicolumn{8}{|c|}{ HOMENS } & \multicolumn{9}{|c|}{ MULHERES } & \multirow[b]{2}{*}{$\underset{\frac{1}{6}}{\frac{1}{6}}$} \\
\hline & P1 & P2 & P3 & P4 & P5 & P6 & P7 & 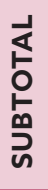 & P8 & P9 & P10 & P11 & P12 & P13 & P14 & P15 & $\begin{array}{l}\frac{1}{5} \\
\frac{5}{\circ} \\
\frac{1}{\infty} \\
\stackrel{0}{n}\end{array}$ & \\
\hline $\begin{array}{l}\text { Adequação do grau de } \\
\text { dificuldade do exame }\end{array}$ & $\checkmark$ & & $\checkmark$ & & & & $\checkmark$ & 3 & & $\checkmark$ & & & $\checkmark$ & & $\checkmark$ & $\checkmark$ & 4 & 7 \\
\hline $\begin{array}{l}\text { Diminuição/revisão do } \\
\text { programa }\end{array}$ & & & & $\checkmark$ & $\checkmark$ & & & 2 & $\checkmark$ & & & $\checkmark$ & $\checkmark$ & & $\checkmark$ & & 4 & 6 \\
\hline $\begin{array}{l}\text { Diversificação de } \\
\text { metodologias de ensino }\end{array}$ & $\checkmark$ & & & $\checkmark$ & & $\checkmark$ & & 3 & & & $\checkmark$ & & & & & & 1 & 4 \\
\hline $\begin{array}{l}\text { Realização do exame no } \\
12^{\circ} \text { ano }\end{array}$ & & & & $\checkmark$ & & & $\checkmark$ & 2 & & & & & & $\checkmark$ & & & 1 & 3 \\
\hline $\begin{array}{l}\text { Trabalho de } \\
\text { competências de } \\
\text { leitura, interpretação e } \\
\text { comunicação }\end{array}$ & & $\checkmark$ & & & $\checkmark$ & & & 2 & & & $\checkmark$ & & & & & & 1 & 3 \\
\hline $\begin{array}{l}\text { Aumento do trabalho } \\
\text { autónomo do aluno }\end{array}$ & & & & & & $\checkmark$ & & 1 & & & & & & $\checkmark$ & & & 1 & 2 \\
\hline $\begin{array}{l}\text { Divisão em duas } \\
\text { disciplinas: Biologia e } \\
\text { Geologia }\end{array}$ & & & & & & & & 0 & & & & $\checkmark$ & & & $\checkmark$ & & 2 & 2 \\
\hline $\begin{array}{l}\text { Promoção de ensino } \\
\text { focado no "treino" para } \\
\text { os exames }\end{array}$ & & & & & & & & 0 & & $\checkmark$ & & & & $\checkmark$ & & & 2 & 2 \\
\hline $\begin{array}{l}\text { Diminuição do } n^{\circ} \\
\text { de questões de } \\
\text { interpretação e análise } \\
\text { documental }\end{array}$ & & & & & & & & 0 & & $\checkmark$ & & & & & & $\checkmark$ & 2 & 2 \\
\hline $\begin{array}{l}\text { Critérios de correção } \\
\text { menos penalizadores }\end{array}$ & & & $\checkmark$ & & & & & 1 & & & & & & & $\checkmark$ & & 1 & 2 \\
\hline $\begin{array}{l}\text { Aumento da componente } \\
\text { prática/laboratorial }\end{array}$ & & $\checkmark$ & & & & & & 1 & $\checkmark$ & & & & & & & & 1 & 2 \\
\hline $\begin{array}{l}\text { Orientação vocacional } \\
\text { dos alunos }\end{array}$ & & & & & & $\checkmark$ & & 1 & & & & & & & & & 0 & 1 \\
\hline $\begin{array}{l}\text { Diversificação dos } \\
\text { instrumentos de } \\
\text { avaliação }\end{array}$ & & & & & & $\checkmark$ & & 1 & & & & & & & & & 0 & 1 \\
\hline $\begin{array}{l}\text { Simplificação dos } \\
\text { manuais }\end{array}$ & & & & & & $\checkmark$ & & 1 & & & & & & & & & 0 & 1 \\
\hline $\begin{array}{l}\text { Melhor relação dos } \\
\text { alunos com a escola }\end{array}$ & & & & & & $\checkmark$ & & 1 & & & & & & & & & 0 & 1 \\
\hline $\begin{array}{l}\text { Aumento da carga } \\
\text { horária da disciplina }\end{array}$ & & & & & & & & 0 & $\checkmark$ & & & & & & & & 1 & 1 \\
\hline $\begin{array}{l}\text { Diminuição do } n^{\circ} \text { de } \\
\text { disciplinas/carga horária }\end{array}$ & & & & & & $\checkmark$ & & 1 & & & & & & & & & 0 & 1 \\
\hline Aulas de apoio & & & & & & $\checkmark$ & & 1 & & & & & & & & & 0 & 1 \\
\hline
\end{tabular}

(continua) 
(continuação)

\begin{tabular}{|c|c|c|c|c|c|c|c|c|c|c|c|c|c|c|c|c|c|c|}
\hline \multirow[b]{2}{*}{$\begin{array}{l}\text { MEDIDAS } \\
\text { PROMOTORAS DE } \\
\text { SUCESSO NO EXAME } \\
\text { DE BG }\end{array}$} & \multicolumn{8}{|c|}{ HOMENS } & \multicolumn{9}{|c|}{ MULHERES } & \multirow[b]{2}{*}{ 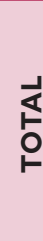 } \\
\hline & P1 & $\mathbf{P 2}$ & P3 & P4 & P5 & P6 & P7 & 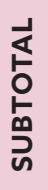 & P8 & P9 & P10 & P11 & P12 & P13 & P14 & P15 & $\begin{array}{l}\frac{1}{5} \\
\frac{1}{0} \\
\frac{1}{0} \\
\frac{0}{n}\end{array}$ & \\
\hline $\begin{array}{l}\text { Articulação horizontal e } \\
\text { vertical }\end{array}$ & & & & & $\checkmark$ & & & 1 & & & & & & & & & 0 & 1 \\
\hline Eliminação da Geologia & & & & & $\checkmark$ & & & 1 & & & & & & & & & 0 & 1 \\
\hline $\begin{array}{l}\text { Formação para } \\
\text { professores }\end{array}$ & & & & $\checkmark$ & & & & 1 & & & & & & & & & 0 & 1 \\
\hline $\begin{array}{l}\text { Alargamento do } \\
\text { intervalo temporal entre } \\
\text { exames }\end{array}$ & & & & & & & & 0 & & $\checkmark$ & & & & & & & 1 & 1 \\
\hline $\begin{array}{l}\text { Diminuição do } n^{\circ} \text { de } \\
\text { alunos por turma }\end{array}$ & $\checkmark$ & & & & & & & 1 & & & & & & & & & 0 & 1 \\
\hline
\end{tabular}

Fonte: Elaboração dos autores.

As principais são: a adequação do grau de dificuldade do exame (sete professores, três homens e quatro mulheres) - "[...] tornar o exame com um nível de dificuldade adequado ao que é exigido no secundário. Não podemos estar a exigir demasiado no exame, ou pedir o que não é pedido na escola" (P3) - e a redução e revisão do programa da disciplina (seis professores, dois homens e quatro mulheres). Em menor número, referem a diversificação de metodologias de ensino nas aulas, refletindo sobre as suas próprias práticas, a realização do exame no final do $12^{\circ}$ ano, para os alunos terem uma maior maturidade, e a necessidade de trabalhar com os alunos, em todos os ciclos, as competências de leitura, interpretação e comunicação.

Mais uma vez, é visível a maior preocupação das professoras com a dimensão exagerada do programa da disciplina como fator de insucesso no exame. No entanto, apenas docentes do sexo masculino referem a necessidade de diversificar metodologias de ensino nas suas aulas. Por outro lado, os professores do sexo masculino apresentam uma maior variedade de medidas promotoras de sucesso dos alunos no exame da disciplina de Biologia e Geologia.

Medidas para promover o sucesso dos rapazes no exame nacional de Biologia e Geologia

Quando questionados sobre a pertinência de se adotarem medidas para a promoção do sucesso especificamente entre os rapazes (Quadro 18), a maioria (nove professores, três do sexo masculino e seis do sexo feminino) não concorda, porque pensa que as diferenças de desempenho ocorrem simplesmente porque as alunas trabalham mais do que os alunos, embora nunca reflitam por que razões isso aconteça, e, como tal, não veem necessidade de tomar medidas específicas. "Eu acho que isso é uma coisa que será sempre assim. Não se vai trabalhar de maneira diferente 
com os rapazes e com as raparigas. As diferenças de género são sempre diferenças, e eles vão ter de lidar com isso" (P14).

Os professores, maioritariamente do sexo masculino, que pensam ser pertinente a adoção de medidas para a promoção do sucesso dos rapazes, mostram dificuldade em propor medidas, o que mostra que o sucesso por sexo não é frequentemente discutido em ambiente escolar. Propõem a diminuição do número de alunos por turma para se poder fazer um ensino mais individualizado, atendendo às especificidades de cada aluno, medidas extraescola, fazendo depender as atividades desportivas do desempenho escolar, a valorização de outros instrumentos de avaliação para além dos testes escritos de avaliação e uma abordagem mais prática e menos teórica da disciplina.

\section{QUADRO 18 - Opinião dos professores sobre a adoção de medidas para promover o sucesso dos rapazes no exame de BG}

\begin{tabular}{|c|c|c|c|c|c|c|c|c|c|c|c|c|c|c|c|c|c|c|}
\hline \multirow[b]{2}{*}{$\begin{array}{l}\text { ADOÇÃO DE MEDIDAS } \\
\text { PROMOTORAS } \\
\text { DE SUCESSO DOS } \\
\text { RAPAZES NO EXAME } \\
\text { DE BG }\end{array}$} & \multicolumn{8}{|c|}{ HOMENS } & \multicolumn{9}{|c|}{ MULHERES } & \multirow[b]{2}{*}{ 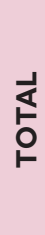 } \\
\hline & P1 & $\mathbf{P 2}$ & P3 & P4 & P5 & P6 & P7 & $\begin{array}{l}\frac{1}{5} \\
\frac{0}{0} \\
\frac{1}{0} \\
\frac{0}{n}\end{array}$ & P8 & P9 & P10 & P11 & P12 & P13 & P14 & P15 & $\begin{array}{l}\frac{1}{5} \\
\text { o } \\
\frac{1}{0} \\
\text { วั }\end{array}$ & \\
\hline Não & & & $\checkmark$ & & & $\checkmark$ & $\checkmark$ & 3 & & $\checkmark$ & & $\checkmark$ & $\checkmark$ & $\checkmark$ & $\checkmark$ & $\checkmark$ & 6 & 9 \\
\hline Sim & $\checkmark$ & $\checkmark$ & & $\checkmark$ & $\checkmark$ & & & 4 & $\checkmark$ & & $\checkmark$ & & & & & & 2 & 6 \\
\hline
\end{tabular}

Fonte: Elaboração dos autores.

Nessa questão, é notória a maior preocupação dos docentes do sexo masculino, sendo mais favoráveis à introdução de medidas para promover o sucesso especificamente dos rapazes, depois de o fenómeno ser bem estudado, embora lhes seja muito difícil a reflexão sobre o problema do insucesso por sexo.

\section{DISCUSSÃO E CONCLUSÕES}

Através da análise destes resultados, percebemos que, quando os professores refletem sobre as causas do insucesso, seja na disciplina, seja no exame, mencionam razões relacionadas a fatores inerentes ao sistema, como o programa da disciplina, com as características da prova como instrumento de avaliação, ou com as dificuldades dos alunos. Raramente refletem nas suas práticas pedagógicas e avaliativas e nas suas conceções de ensino, de aprendizagem e de avaliação, ou seja, externalizam a responsabilidade desse insucesso, embora compreendam que o facto de existir exame condicione as suas práticas pedagógicas e avaliativas. Mas essa alteração de práticas surge como um fatalismo que não depende da sua vontade, o que pode denotar uma capacidade reduzida de reflexão sobre o seu trabalho, tal 
como constatou o relatório OECD Reviews of Evaluation and Assessment in Education: Portugal 2012 (SANTIAGO et al., 2012) e que também já tínhamos constatado em estudo anterior (LOPES, 2013).

Sobressai deste estudo a grande influência que a existência de exame nacional tem nas práticas pedagógicas e avaliativas dos docentes, no currículo, nas conceções de avaliação que são valorizadas e na relação entre professores e alunos. Os professores modificaram as suas práticas apenas em função dos resultados dos alunos, e não em função da qualidade do ensino. Focam-se em atividades e métodos orientados para o sucesso no exame, aplicam nos seus testes de avaliação a estrutura e os critérios de correção e classificação dos exames, para familiarizarem os alunos àquele tipo de prova, com vista a treiná-los. Estudos anteriores (ROSÁRIO, 2007; MADUREIRA, 2011; SOUSA, 2011; LOPES, 2013) chegaram aos mesmos resultados, demonstrando bem como os princípios que devem gerir a sala de aula, a procura de melhores e mais ricas aprendizagens por parte dos alunos, perverteram-se. A prioridade dos professores é cumprir o programa, mas valorizando apenas o que pensam que será avaliado pelo exame, ou seja, as competências do domínio cognitivo. A prova escrita passou a ser o único instrumento de avaliação válido, reforçando a conceção psicométrica da avaliação como medição e certificação, desvalorizando a avaliação formativa como reguladora, orientadora, indutora de melhorias conjuntas nas práticas de professores e alunos, desvirtuando as relações pedagógicas. No ensino secundário da disciplina de Biologia e Geologia, instalou-se o "teaching to the test", já que todo o processo de aprendizagem se centra no treino para o exame e nos resultados imediatos dos alunos e não na qualidade das aprendizagens (NAVAS; ALCARAZ; SOLA, 2017).

Assim, parece-nos de grande importância proporcionar aos professores formação como oportunidade de desenvolvimento profissional, refletindo nas suas práticas de ensino e nas suas conceções de aprendizagem e de avaliação, no sentido de os capacitar para se libertarem do jugo do exame.

Os docentes consideram o exame difícil e desadequado para a idade e maturidade dos alunos por motivos variados: elevado grau de exigência cognitiva, linguagem complexa, elevado grau de complexidade da análise documental, questões pouco claras e ambíguas e critérios de correção e classificação do exame muito penalizadores, sentindo um grande incómodo na aplicação desses critérios quando da correção e classificação dos exames por serem obrigados a aplicá-los sem com eles concordar. Estes resultados estão em concordância com estudos anteriores (LOPES, 2013), assim como vão de encontro às perceções dos alunos (LOPES, 2013) que consideram que a prova nacional apresenta um nível de dificuldade exageramente elevado e desfasado da realidade das aulas. No entanto, os docentes passaram a aplicar nos testes de avaliação que realizam ao longo do ano 
a mesma estrutura e os mesmos critérios, pensando que este mimetismo é benéfico para os alunos. Estas conclusões vão de encontro às descritas em vários outros estudos nacionais (ROSÁRIO, 2007; MADUREIRA, 2011; SOUSA, 2011; SALGADO, 2012, LOPES, 2013) e mostram bem como o exame funciona como instrumento de controlo e limitação das ações dos professores (ESTEBAN, 2004), que veem a sua autonomia restringida (MÉNDEZ, 2001).

Perante os fatores de dificuldade que os professores encontram no exame, é imprescindível analisar a qualidade e a validade do exame enquanto instrumento de avaliação. De igual modo, em face da desadequação entre o programa, o que é ensinado e o que é avaliado, que os professores referem, parece-nos também importante, tal como afirmam Raposo e Freire (2008, p. 123), “[...] aproximar a lógica do exame ao currículo". Além disso, percebendo a disparidade do exame em relação à realidade da sala de aula e analisando o insucesso dos resultados, pensamos que, no imediato, por uma questão de justiça para com os alunos, e até ética, é impreterível retirar a nota mínima de acesso das provas específicas (9,5 valores).

Das medidas apontadas para o sucesso dos alunos na disciplina e no exame, destaca-se a ideia de que é urgente a redução, revisão e atualização do programa da disciplina que condiciona o funcionamento das aulas, levando a práticas expositivas, com uma fraca diversificação de metodologias, e a uma preocupação exagerada com o tempo necessário para o cumprir. De realçar que o programa da disciplina se mantém inalterado há quase duas décadas (o programa de $10^{\circ}$ ano data de 2001 , e o programa de $11^{\circ}$ data de 2003), tendo sido já apontado como causa de insucesso noutro estudo efetuado por nós (LOPES, 2013).

Em Portugal, quando se analisam os resultados dos alunos no exame, questiona-se a qualidade das aprendizagens dos alunos e a competência profissional dos professores. No entanto, é tempo de analisar a qualidade das questões e as competências cognitivas que as provas exigem, sendo fundamental investigar se as provas avaliam aquilo que se pretende medir, ou seja, a sua validade.

Quanto às diferenças entre as perceções de professores e professoras, é nítida a maior preocupação delas com o cumprimento do programa da disciplina e maior apreensão pela influência que a existência do exame exerce nas suas práticas, ou talvez tenham maior consciência dessa influência, já que são elas que mais referem a utilização de estratégias de treino, orientando todo o processo de ensino para o sucesso no exame.

Outra diferença verifica-se nas perceções de professores e professoras acerca do insucesso dos alunos em função do sexo. Há uma maior preocupação dos docentes do sexo masculino com esta problemática, sendo mais favoráveis à introdução de medidas para promover o sucesso especificamente dos rapazes, depois de o fenómeno ser bem estudado, embora lhes seja muito difícil a reflexão sobre o problema 
do insucesso por sexo. São claramente os professores que mais procuram as causas dessa diferença de desempenho, diversificando e aprofundando mais as explicações para a desvantagem dos rapazes. As professoras atribuem o insucesso deles apenas à falta de trabalho e de empenho e ao facto de os rapazes serem mais imaturos, ou seja, apenas referem causas relacionadas aos próprios alunos, nunca refletindo sobre as causas que estariam na base das diferenças de atitudes perante a escola que percecionam. Este é um problema multifatorial, muito complexo, que os professores, sobretudo as professoras, abordam de uma forma muito simplista e superficial, o que mostra bem como a questão não faz parte das suas preocupações e que não há reflexão sobre essa problemática em ambiente escolar, o que vai de encontro aos resultados apresentados no relatório Abandono e insucesso escolar: construir uma perspetiva de género (CAVACO et al., 2015).

Estudos têm mostrado que os professores, no que diz respeito aos problemas relacionados ao género em meio escolar, têm, frequentemente, atitudes conservadoras e expectativas tradicionais sobre os estereótipos de género (EURYDICE, 2010), atitudes essas que também se revelaram neste estudo, já que os professores atribuem o pior desempenho dos rapazes a características estereotipadas e não pensam ser importante adotar medidas para promover o sucesso dos rapazes numa perspetiva de equidade de género e de igualdade de oportunidades. É, assim, imprescindível trazer para a discussão esta problemática para refletirmos sobre as causas dessas diferenças para as compreendermos e podermos atuar antes que estas se agudizem.

\section{REFERÊNCIAS}

CAVACO, C.; ALVES, N.; GUIMARÃES, P.; FELICIANO, P. Abandono e insucesso escolar: construir uma perspetiva de género. Lisboa: Instituto de Educação, 2015.

ESTEBAN, M. T. A avaliação no cotidiano escolar. In: ESTEBAN, M. T. (org.). Avaliação: uma prática em busca de novos sentidos. Rio de Janeiro: DP\&A, 2004. p. 7-27.

EURYDICE. Exames nacionais de alunos na Europa: objetivos, organização e utilização de resultados. Lisboa: Gabinete de Estatísticae Planeamento da Educação, Ministério da Educação, 2009.

EURYDICE. Diferenças de género nos resultados escolares: estudo sobre as medidas tomadas e a situação actual na Europa. Lisboa: Gabinete de Estatísticae Planeamento da Educação, Ministério da Educação, 2010.

FERNANDES, D. A avaliação das aprendizagens no Sistema Educativo Português. Educação e Pesquisa, São Paulo, v. 33, n. 3, p. 581-600, set./dez. 2007.

FERNANDES, D. Avaliações externas e melhoria das aprendizagens dos alunos: questões críticas de uma relação (im)possível. In: SEMINÁRIO AVALIAÇÃO EXTERNA E QUALIDADE DAS APRENDIZAGENS, 1., 2014, Lisboa. Conferência [...]. Lisboa: CNE, 2014. 
GARCIA, R. L. A avaliação e suas implicações no fracasso/sucesso. In: Esteban, M. T. (org.). Avaliação: uma prática em busca de novos sentidos. Rio de Janeiro: DP\&A, 2004. p. 29-47.

LOPES, T. F. F. Perceções de professores, alunos e encarregados de educação sobre o (in)sucesso na disciplina de Biologia e Geologia. 2013. 260 f. Dissertação (Mestrado em Ciências da Educação) Instituto de Educação, Universidade do Minho, Braga, 2013.

LOPES, T.; PRECIOSO, J. Evolução do insucesso escolar nos exames nacionais do ensino secundário, por sexo, em Portugal. Revista Iberoamericana de Evaluación Educativa, Madrid, v. 11, n. 2, p. 53-69, maio 2018.

MADUREIRA, M. A influência dos exames nacionais de Física e Química A e respetivos resultados nas práticas de ensino e de avaliação dos professores. 2011. 129 f. Dissertação (Mestrado em Ciências da Educação) - Universidade do Minho, Braga, 2011.

MARQUES, M.; SOUSA, J.; COSTA, N.; PACHECO, J. A. Efeitos da avaliação externa das aprendizagens no desenvolvimento profissional de professores de Matemática do ensino básico em Portugal. Revista Meta: Avaliação, Rio de Janeiro, v. 7, n. 19, p. 58-84, jan./abr. 2015.

MÉNDEZ, J. Evaluar para conocer, examinar para excluir. Madrid: Ediciones Morata, 2001.

MONS, N. Theoretical and real effects of standardised assessment. [S.1]: Eurydice Network, 2009.

NAVAS, M.; ALCARAZ, N.; SOLA, M. Evaluación y pruebas estandarizadas: una reflexión sobre el sentido, utilidad y efectos de estas pruebas en el campo educativo. Revista Iberoamericana de Evaluación Educativa, Madrid, v. 10, n. 1, p. 51-67, maio 2017.

OCDE. The ABC of Gender Equality in Education: Aptitude, Behaviour, Confidence. Paris: OECD Publishing, 2015.

PORTUGAL. Ministério da Educação. Direção-Geral de Estatísticas da Educação e Ciência. Disciplinas escolhidas e concluidas pelos alunos diplomados nos cursos cientifico-humanisticos, 2016/17. Lisboa: DGEEC, 2018.

PORTUGAL. Direção-Geral de Estatísticas da Educação e Ciência. Perfil do Aluno 2017/2018. Lisboa: DGEEC, 2019.

RAPOSO, P.; FREIRE, A. Avaliação das aprendizagens: perspectivas de professores de Física e Química. Revista da Educação, v. 16, n. 1, p. 97-127, 2008.

ROSÁRIO, M. A. do. Influência do exame nacional do $9^{\circ}$ ano de escolaridade nas práticas de ensino e de avaliação em Matemática. 2007. 141 f. Dissertação (Mestrado em Ciências da Educação) - Instituto de Educação e Psicologia, Universidade do Minho, Braga, 2007.

SALGADO, R. M. F. da S. O (in)sucesso em Física e Química A: um estudo com alunos e professores de uma Escola Secundária de Guimarães. 2012. 170 f. Dissertação (Mestrado em Ciências da Educação) - Instituto da Educação, Universidade do Minho, Braga, 2012.

SANTIAGO, P.; DONALDSON, G.; LOONEY, A.; NUSCHE, D. OECD Reviews of evaluation and assessment in education: Portugal 2012. Paris: OECD Publishing, 2012. 
SOUSA, L. D. de. O exame nacional de Física e Química A e o seu impacte na prática pedagógica dos professores: um estudo centrado nas atividades laboratoriais. 2011. 170 f. Dissertação (Mestrado em Ciências da Educação) - Instituto de Educação, Universidade do Minho, Braga, 2011.

VERGARA, C. Los efectos adversos de una evaluación nacional sobre las prácticas de enseñanza de las matemáticas: el caso de SIMCE en Chile. Revista Iberoamericana de Evaluación Educativa, Madrid, v. 10, n. 1, p. 69-87, maio 2017.

\section{COMO CITAR ESTE ARTIGO}

LOPES, Teresa; PRECIOSO, José. Insucesso de alunos e alunas no exame de Biologia e Geologia: estudo com professores. Estudos em Avaliação Educacional, São Paulo, v. 32, e06848, 2021.

DOI: https://doi.org/10.18222/eae.v32.6848 